\title{
The Use of GPR and Microwave Tomography for the Assessment of the Internal Structure of Hollow Trees
}

\author{
Fabio Tosti, Senior Member, IEEE, Gianluca Gennarelli, Livia Lantini, Student Member, IEEE, \\ Ilaria Catapano, Francesco Soldovieri, Senior Member, IEEE, Iraklis Giannakis, Amir M. Alani
}

\begin{abstract}
Internal decays in trees can rapidly escalate into a full decomposition of the inner structural layer, i.e., the "heartwood" layer, due to the action of aggressive diseases and fungal infections. This process leads to the formation of big cavities and hollows, which remain surrounded by the sapwood layer only. Estimating the thickness of the sapwood layer with a high degree of accuracy is therefore crucial for a correct assessment of the structural integrity of hollow trees, as well as an extremely challenging task. In this context, ground-penetrating radar (GPR) has proven effective in providing details of the internal structure of trees. Nevertheless, the existing GPR processing methods still offer limited information on their internal configuration. This study investigates the effectiveness of GPR enhanced by a microwave tomography inversion approach in the assessment of hollow trees. To this aim, a living hollow tree was investigated by performing a set of pseudo-circular scans along the bark perimeter with a hand-held common-offset GPR system. The tree was then felled, and sections were cut for testing purposes. A dedicated data processing framework was developed and tested through numerical simulations of hollow tree sections. The internal structure of the real trunk was therefore reconstructed via a tomographic imaging approach and the outcomes were quantitatively analysed by way of comparison with the real sections' main geometric features. The tomographic approach has proven very accurate in locating the sapwood-cavity interface as well as in the evaluation of the sapwood layer thickness, with a centimetre prediction accuracy.
\end{abstract}

Keywords - ground-penetrating radar (GPR); hollow trees; sapwood layer thickness; microwave tomography; non-destructive testing (NDT); tree health monitoring.

\section{INTRODUCTION}

Tree diseases affect the natural ecosystems governing the growth of forests and the coexistence of plants and pathogens is essential for both to survive. Although this is a natural process self-regulated by the environment, the amount and the incidence of invasive diseases are continuously increasing [1]. The effects of climate change with the progressive increase in temperatures have contributed to foster the spread and proliferation of bacteria and fungi, which are responsible for many diseases [2, 3]. Furthermore, anthropic activities including human population growth [4], worldwide travel [2]

Fabio Tosti, Livia Lantini and Amir M. Alani are with the School of Computing and Engineering, University of West London, London, W5 5RF (Fabio.Tosti@uwl.ac.uk, Livia.Lantini@uwl.ac.uk, Amir.Alani@uwl.ac.uk). (*Corresponding author's email: Fabio.Tosti@uwl.ac.uk)

Gianluca Gennarelli, Ilaria Catapano and Francesco Soldovieri are with the Institute for Electromagnetic Sensing of the Environment, National Research and international plant [5] and timber trade [6] have contributed to breaking down environmental barriers for protection of ecosystems, altering the balance of natural habitats. In this regard, Anderson et al. [1] state that pathogens affecting new geographical areas have increased their impact, or they have evolved or recently been discovered and classified as emerging infectious diseases (EIDs). Due to the rise in the EIDs' spread [7], entire forests are decaying, and several tree species are threatened with extinction [8].

Depending on the disease, different parts of a plant, such as the roots, the foliage, or the stem, can be affected. Overall, the structure of a tree trunk can be mainly divided into three main components, i.e., the bark, the sapwood and the heartwood [9]. The bark has the function to protect the tree from external agents [10], the sapwood is responsible for the transportation of water and minerals from the roots to the leaves [11] and the heartwood has the primary function to provide structural strength, as it is no longer involved in nutrition transport processes [11].

Tree trunks are affected by various injuries and wounds [12, 13]. Once damage occurs, fungi and bacteria can penetrate the bark, germinate within the wood tissues, and cause decay in the sapwood and the heartwood. Some fungi are associated with the heart rot disease $[14,15]$. This pathology causes wood decay at the centre of the trunks or the branches and it can escalate into the heartwood decomposition. Consequently, the latter layer can soften and rot, leading to the formation of a tree hollow [16, 17].

Nevertheless, it is worth noting that tree hollows do not necessarily jeopardise the tree's survival [12], as the dead tissues of the heartwood are not involved in the tree biological and physiological processes [11]. To this effect, it is important to note that a hollow tree can keep increasing in size [18], as the transportation and storage of nutrients take place in the living section of the wood, i.e., the sapwood [11]. Nevertheless, the decomposition of the heartwood, the primary purpose of which is to provide structural support [11], and the potential formation of hollows, may exert considerable influence on the tree's stability. Strength of the stem is diminished by the formation of

Council of Italy, 80124 Naples, Italy (gennarelli.g@irea.cnr.it, catapano.i@irea.cnr.it, soldovieri.f@irea.cnr.it).

Iraklis Giannakis is with the School of Geosciences, University of Aberdeen Meston Building, Kings College, Aberdeen, AB24 3FX (iraklis.giannakis@abdn.ac.uk). 
cavities and hollows, making trees structurally unstable and more likely to fall under the effect of external forces, such as wind loads [19]. This is rather unsafe in urban environments, as trees' structural instability can harm the safety of people, structures and infrastructures [19].

As well as the early-stage signs of disease [20], it is crucial to assess the main characteristics of a hollow tree, such as the bark and the sapwood thicknesses and the presence of any transversal crack on the sapwood, to verify its structural integrity. Simple approaches based on the operator's experience, such as locating decay by sounding the tree, are still commonly used. However, these techniques are not very accurate, as they can only determine the existence of decayed wood, whereas no information can be obtained on the size and stage of the decay [21]. Destructive techniques, such as the core-drilling method [22], are also frequently used for the evaluation of the internal tree structure. However, the effectiveness of these methods is limited by their invasiveness. In addition, they are time-consuming, laborious, and they often cause permanent damage to the tree itself by exposing it to further infection by pests or fungi [23, 24]. Furthermore, destructive testing methods provide information only at the time/space position of the sampling section and are thus useless for analysing decay processes.

On the other hand, the use of non-destructive testing (NDT) methods in this application area is expanding rapidly due to their flexibility, versatility and the provision of accurate outcomes at relatively low costs. Usage of NDTs also allows for a routine-based monitoring and longer-term strategies for tree management. In this framework, use of NDT methods such as resistograph testing [25], electrical resistivity tomography (ERT) [26], ultrasound tomography [27], infrared thermography [28], X-ray tomography [29] and signal processing approaches, e.g., the microwave tomography [30], have been reported in this area of endeavour.

Ground-Penetrating Radar (GPR) is acknowledged as a compelling non-destructive geophysical device for tree monitoring. Numerous experiments have been recently carried out on the effectiveness of GPR for large-scale forestry engineering investigations [31].

A technique based on the interpretation of B-Scans in polar coordinates is described in [32,33], a layer-based detection is presented in [34], a hyperbola fitting approach is discussed in [35] and a migration-based method is reported in [36]. Regardless of these signal processing approaches, tomographic techniques have proven effective in tree trunks monitoring in view of the closed surface configuration with a dense amount of measurement points. Here, we consider a microwave tomography approach as a data processing step to produce an image of the tree section. Microwave tomographic approaches have been designed and assessed for cylindrical structures in biomedical applications [37, 38], by resorting to inversion schemes mainly based on linear approximations of the electromagnetic scattering phenomenon [39-43]. Further examples of these implementation methods can be found in the imaging of other cylinder-like structures such as columns [44] and pillars [45].

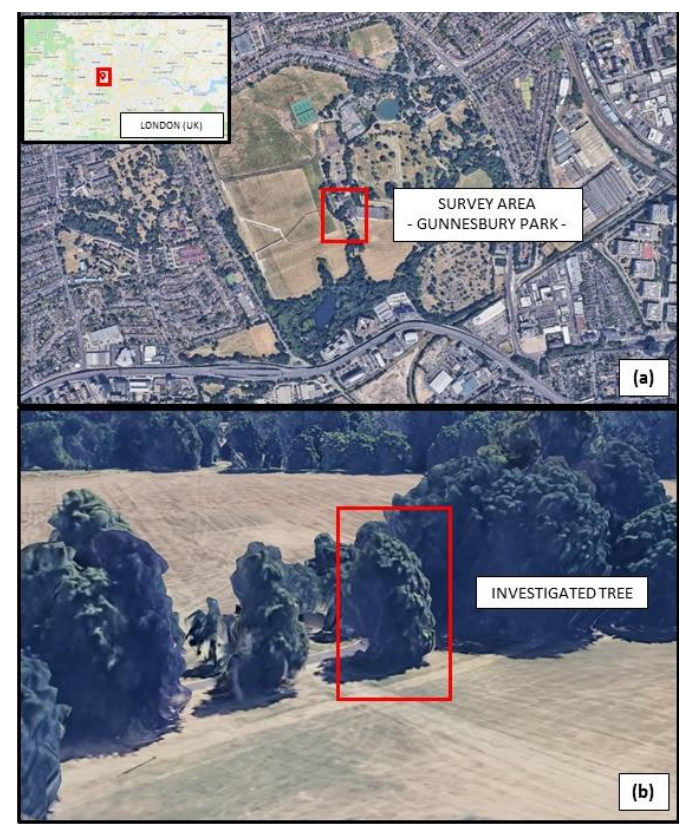

Fig. 1. Test site location at Gunnesbury Park, London, UK. An overview of the area (a) and an aerial view of the investigated "Acer Pseudoplatanus" tree (b).

A similar method has been recently implemented for the assessment of the internal structure of tree trunks, with promising results $[30,35,46]$. Specifically, the imaging approach in [46] has been assessed through numerical models of tree trunks and controlled laboratory experiments based on dry tree logs with small cavities.

In this study, a step forward is taken by the provision of GPR field tests on a living hollow tree. The main research scope is to characterise the thickness of the sapwood (structural) layer by the identification of the sapwood-cavity interface. To accomplish this aim, GPR data were collected on the tree and processed by a microwave tomographic approach, which exploits accurate information about the actual shape and measurement points along the tree section.

To elaborate, following the data collection on site, the investigated tree was felled, and several sections were cut for testing purposes. This allowed to compare the microwave tomographic images with the ground-truth sections. It is important to note that the GPR inspection of living trees is still an open issue that poses some relevant technical challenges. First, the acquisition of good quality data can be hindered by the irregular shape of the tree and its surface roughness. Moreover, ringing effects caused by antenna mismatching dominate the early time response in the radargrams. Therefore, as it will be shown in this paper, a proper data processing framework is crucial to achieve reliable images of the tree cross-section.

The paper is organised as follows. Section II reports a description of the test site and the analysis of the raw data. Section III discusses the proposed data processing framework and the results of the tomographic reconstructions follow in Sec. IV. Conclusions are reported in Sec. V. 


\section{MEASUREMENT SURVEY AND RAW DATA}

\section{A. The Test Site}

The survey was performed at Gunnersbury Park, Ealing, London (United Kingdom) (see Fig. 1). The investigated sycamore (Acer Pseudoplatanus) tree was selected under the advice of the London Borough of Ealing's Tree Service. This tree was located along a tree-lined avenue inside the park, approximately $10 \mathrm{~m}$ distant from other adjacent trees.

As reported by the registered charity "Friends of Gunnersbury Park and Museum" [47], the investigated tree had been monitored since 2010, when a large cavity was found in the stem [48]. Over the past decade, the tree conditions had deteriorated, as increasing rotting and decay had been reported. This created significant safety concerns to the public and, hence, it was decided to fell the tree. The GPR survey was planned before the scheduled tree felling to collect reference information on the trunk internal structure, including the size of the hollow and the thickness of the sapwood layer. In this way, the effectiveness of the GPR equipment and the viability of the proposed processing framework were assessed by comparing the reconstructed images with the evidence from the actual tree cross-sections.

\section{B. The GPR Equipment and the Surveying Technique}

The "Aladdin" 2-GHz hand-held antenna system, manufactured by IDS GeoRadar (Part of Hexagon), was deployed for testing purposes. The radargrams were collected with a time-step $\Delta t=6.25 \cdot 10^{-11} \mathrm{~s}$ and a spatial step $\Delta s=1 \mathrm{~cm}$ between the traces. The survey methodology was based on pseudo-circular perimetric GPR acquisitions. Each measurement was accurately positioned based on the distance (calculated using the wheel encoder attached to the antenna) from a given reference starting point, using an arc length parameterisation approach, as described in [35].

A number of 14 scans encircling the tree were performed parallel to the ground, spaced $0.1 \mathrm{~m}$ each to one another. Hence, the investigated area was a "cylinder" of $1.3 \mathrm{~m}$ height (Fig. 2).

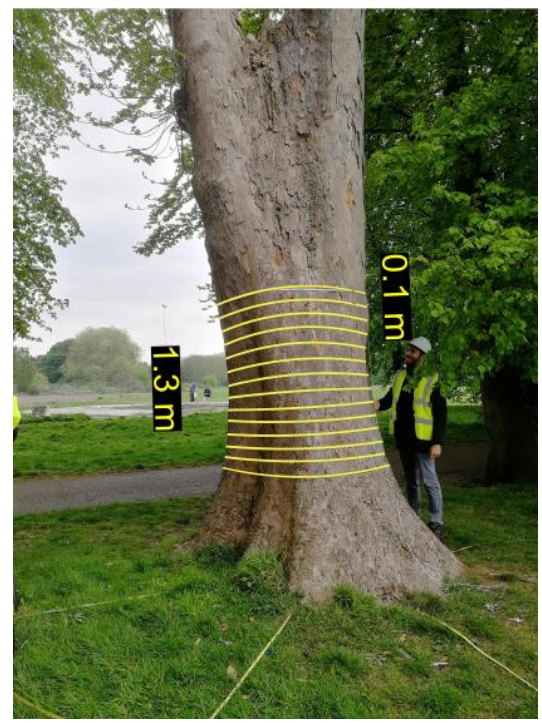

Fig. 2 GPR measurement layout around the investigated "Acer Pseudoplatanus" tree.
The first scan was taken at the bottom of the tree $(h=0 \mathrm{~m})$, whereas the final scan was collected at $h=1.3 \mathrm{~m}$. The average radius of the circle approximating the contour of the tree across the investigated section was estimated to be equal to $0.63 \mathrm{~m}$. Following the GPR survey, the tree was felled, and the investigated section was cut into $\sim 0.2 \mathrm{~m}$ thick slices, which were subsequently used for validation purposes.

\section{Raw Data Analysis}

To assess the effectiveness of GPR in detecting the tree cavity, geometric representations of the tree sections located at heights $h=0 \mathrm{~m}\left(\mathrm{P}_{1}\right), h=0.6 \mathrm{~m}\left(\mathrm{P}_{2}\right)$ and $h=1.3 \mathrm{~m}\left(\mathrm{P}_{3}\right)$, respectively, were produced based on the visual information collected after the tree felling operation (see Fig. 3). These sections provide a comprehensive framework of the overall inspected volume of the trunk from bottom to top.

Table I lists the main geometric characteristics of the abovementioned sections. $R_{i}$ and $r_{i}$ denote the outer and inner radii of the cross-section at the $i^{\text {th }}$ inspection height; $\bar{R}$ is the average radius of the trunk. $\bar{R}-\bar{r}$ is the average thickness of the sapwood; $\max \left|R_{i}-r_{i}\right|$ is the maximum $i^{\text {th }}$ sapwood thickness; $\min \left|R_{i}-r_{i}\right|$ is the minimum $i^{\text {th }}$ sapwood thickness. Moreover, $v$ is the percentage ratio expressing the sapwood area $A_{S}$ over the full cross-section area $A_{T}$ (i.e., the summation of the sapwood $\left(A_{S}\right)$ and the hollow areas $\left.\left(A_{H}\right)\right) ; \rho$ is the percentage rate of sapwood thickness reduction considering the thickness at the base (i.e., section $\mathrm{P}_{1}$ ) as the reference. From the data listed in Tab. I, it is clear how the thickness of the sapwood drastically decreases from bottom to top, being $\rho=28.14 \%$ at middle section, and $\rho=44.98 \%$ at the top section inspected. The average sapwood thickness $\bar{R}-\bar{r}$ is $20.17 \mathrm{~cm}\left(\mathrm{P}_{1}\right), 16.65 \mathrm{~cm}$ $\left(\mathrm{P}_{2}\right)$ and $11.63 \mathrm{~cm}\left(\mathrm{P}_{3}\right)$, with local maximum and minimum thickness values consistent with the upward-decreasing trend. It is also interesting to note that the area occupied by the sapwood is relatively similar to the hollow area at sections $\mathrm{P}_{1}$ and $\mathrm{P}_{2}$, whereas it decreases up to one third at section $\mathrm{P}_{3}$ (i.e., $v$ $=33.83 \%$ ). This behaviour is observed regardless from the fact that the full cross-section area decreases from the base to the middle section and increases from the middle to the top section.

The raw radargrams (B-scans) collected at the considered sections are depicted in Fig. 4. The figures are displayed over a saturated colour scale and highlight a very similar behaviour despite the geometric differences observed for the tree crosssections (see Fig. 3). This claim is also supported by the curves plotted in Fig. 5, where the average traces along the measurement direction for the three scans are compared. Except for a time shift less than $1 \mathrm{~ns}$, the average traces show a similar trend, especially over the first $5 \mathrm{~ns}$ of the time window. A major common trend observed across the radargrams is the presence of significant reflections occurring around same travel time instants from the first radar echo. These reflections are likely related to ringing effects within the antenna as a result of an increased mismatch due to the high dielectric permittivity of the investigated tree. Furthermore, it is worth to mention that the mismatch observed in Fig. 5 can be also partially related to nonoptimal continuous coupling conditions between the radar system and the bark, due to local surface irregularities. 

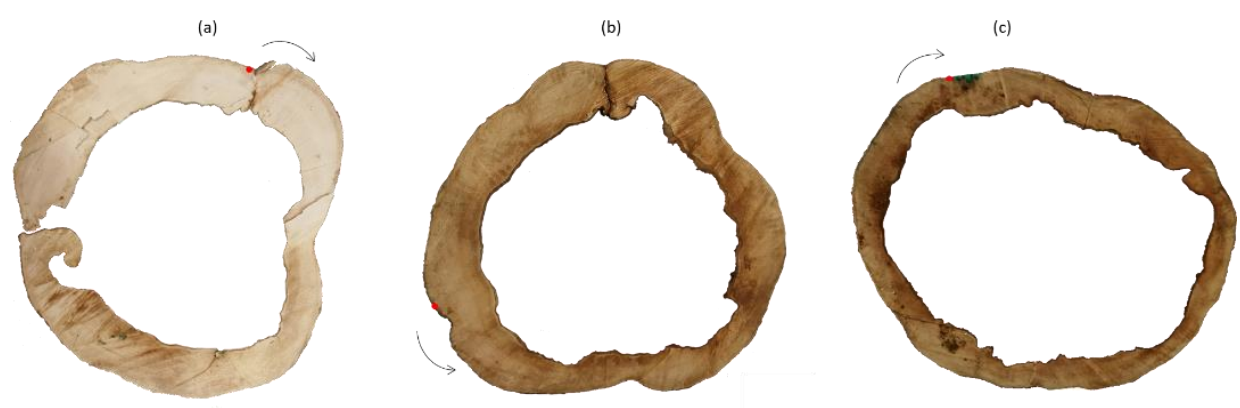

Fig. 3. Plan view of the tree cross-sections at $h=0 \mathrm{~m}$ (a), $h=0.6 \mathrm{~m}$ (b) and $h=1.3 \mathrm{~m}$ (c). The red dot denotes the initial measurement point and the arrow indicates the movement direction of the GPR antenna along the bark.

TABLE I

MAIN GEOMETRIC CHARACTERISTICS OF THE REAL CROSS-SECTIONS CUT FROM THE INVESTIGATED TREE TRUNK

\begin{tabular}{ccccccccc}
\hline \hline Section & $\begin{array}{c}\bar{R} \\
{[\mathrm{~cm}]}\end{array}$ & $\begin{array}{c}\bar{R}-\bar{r} \\
{[\mathrm{~cm}]}\end{array}$ & $\begin{array}{c}\max \left|R_{i}-r_{i}\right| \\
{[\mathrm{cm}]}\end{array}$ & $\begin{array}{c}\min \left|R_{i}-r_{i}\right| \\
{[\mathrm{cm}]}\end{array}$ & $\begin{array}{c}\text { Hollow Area } \\
A_{H} \\
{\left[\mathrm{~cm}^{2}\right]}\end{array}$ & $\begin{array}{c}\text { Sapwood Area } \\
A_{S} \\
{\left[\mathrm{~cm}^{2}\right]}\end{array}$ & $\begin{array}{c}v \\
{[\%]}\end{array}$ & $\begin{array}{c}\rho \\
{[\%]}\end{array}$ \\
\hline $\mathrm{P}_{1}(h=0 \mathrm{~m})$ & 69.31 & 20.17 & 26.84 & 11.19 & 7585.85 & 7505.22 & 49.73 & 0 \\
$\mathrm{P}_{2}(h=0.6 \mathrm{~m})$ & 59.88 & 16.65 & 22.08 & 9.10 & 5871.00 & 5393.52 & 47.88 & 28.14 \\
$\mathrm{P}_{3}(h=1.3 \mathrm{~m})$ & 62.33 & 11.63 & 16.48 & 6.69 & 8075.95 & 4129.68 & 33.83 & 44.98 \\
\hline \hline
\end{tabular}
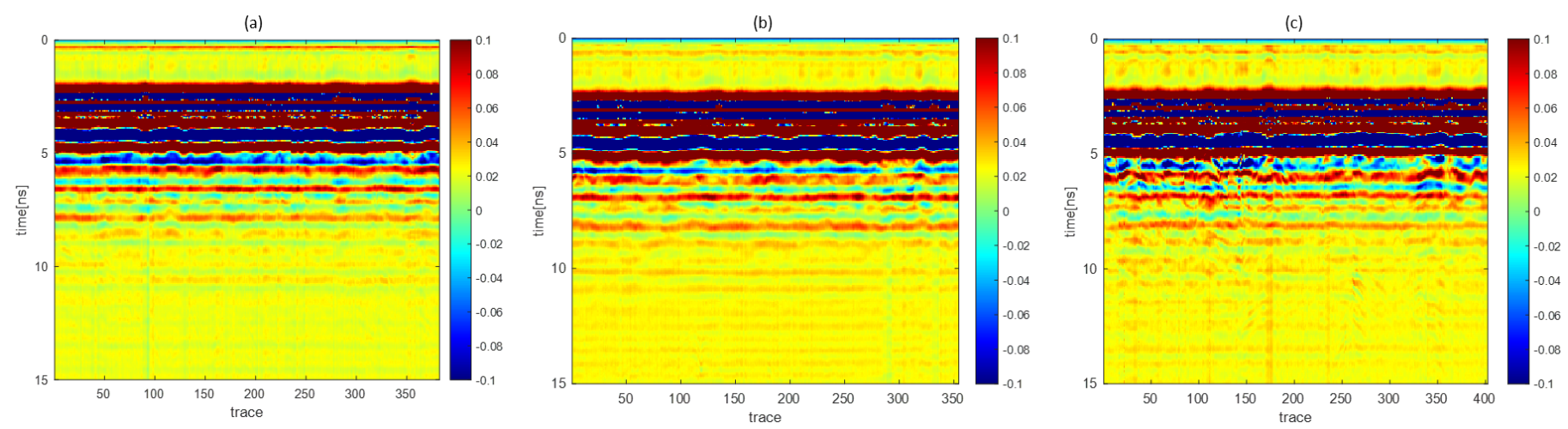

Fig. 4. Raw radargrams collected at the considered tree sections. $h=0 \mathrm{~m}$ (a), $h=0.6 \mathrm{~m}$ (b) and $h=1.3 \mathrm{~m}$ (c).

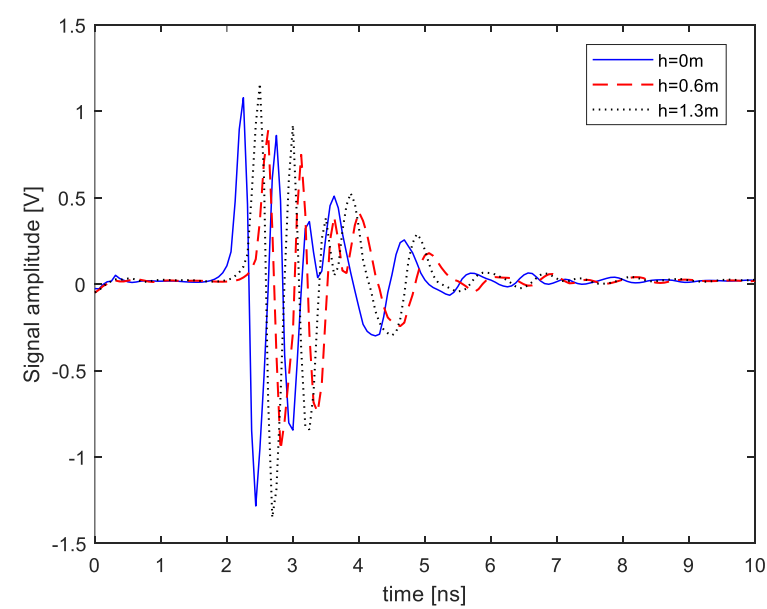

Fig. 5. Average traces of the radargrams collected at the tree sections at $h=0$, $0.6,1.3 \mathrm{~m}$.

According to [50], the sapwood relative dielectric permittivity is the highest compared to the permittivity of the bark and the heartwood tissues, matching the premise of a higher water content due to its main function of being a water nutrient transportation layer. Due to the high permittivity of the sapwood, which can vary in the range 15-30 [49], a mismatching occurs between the GPR antenna impedance and the medium impedance. As a result, a significant ringing arises and overwhelms the response from buried targets. To cope with this problem, time-domain filtering operations $[51,52]$ are required to mitigate the clutter and achieve reliable information. This point will be discussed in more detail in the next section.

\section{PROCESSING STRATEGY: TIME DOMAIN FILTERING AND MICROWAVE TOMOGRAPHY APPROACH}

This section presents the GPR data processing approach with main steps reported in the block diagram of Fig. 6. The raw radargram is processed through several time-domain filtering operations. Following this, a reconstruction procedure, based on the implementation of a microwave tomographic approach and working in the frequency domain, is applied to produce a tomographic image of the tree sections as the final output.

\section{A. Time-Domain Processing}

As shown in Subsect. II C, the raw radargrams are collected in the time-domain and account for the total field, i.e., the direct coupling between the antennas, the reflection from the bark, and 
the field scattered by the inner anomalies. In more detail, the antenna coupling and the ringing effects cause a significant clutter that overwhelms the useful portion of weaker reflections/backscattering produced by the inner tree features. Therefore, a pre-processing is needed to mitigate the clutter before processing the data with the tomographic approach.

The first operation is the zero-time setting, in order to set the zero of the fast-time axis at the air-tree bark interface. Afterwards, a time-gating operation is performed by enforcing to zero the part of the signal where direct coupling and ringing occurrences are dominant. Time-gating is followed by a background removal to eliminate residual coupling and ringing components, which can be considered as spatially constant signal. In terms of the background removal, any individual radar trace (A-scan) is replaced with the difference between its value and the average of all the traces in the ungated part of the radargram. To highlight the effectiveness of the proposed data processing framework, radargrams achieved after the application of the full steps in the time-domain processing (Fig. 7) are first represented and compared with the radargrams obtained by a partial application of the time-domain processing (Fig. 8).

The filtered radargrams are obtained for the tree sections by setting the zero-time at $2.3 \mathrm{~ns}$, the gating-time at $5 \mathrm{~ns}$ and by the application of the background removal, see Fig. 7. To demonstrate the effectiveness of the proposed time-domain processing framework, the radargrams processed by the application of the background removal only are reported in the upper panels of Fig. 8 (i.e., Figs. 8a-c), whereas the radargrams achieved by the application of the time-gating only are reported in the bottom panels of Fig. 8 (i.e., Figs. 8d-e). The filtered radargrams in Figs. 7 and 8 are displayed over the time window 0-12.7 ns since, as mentioned before, the zero time on the raw data has been set equal to 2.3 ns. Differently from those in Fig. 4, all sets of radargrams in Fig. 8 are free from the horizontally constant clutter due to the antenna coupling, although they are still affected by a strong residual clutter. Specifically, the radargrams in the upper panels (Figs. 8a-c) are affected by strong amplitude residual clutter in the early time response (up to about $3 \mathrm{~ns}$ ), which is not fully removed by the background removal, likely related to the effects of non-optimal surface regularity conditions across the full perimeter of the bark.

Conversely, those in the bottom panels (Figs. 8d-f) are affected by a constant clutter occurring over the entire observation time window, with an amplitude comparable with that of the useful signals. Hence, time-gating and background removal are both required to eliminate the residual clutter (see Fig. 7). Of course, since time gating enforces to zero the radargrams up to $5 \mathrm{~ns}$, i.e. in the interval $0-2.7 \mathrm{~ns}$ once setting the zero time, it is not possible to achieve any information about the shallower part of the sapwood. On the other hand, background removal attenuates the signals due to the sapwoodcavity interface occurring at the same travel time.

Regarding the estimation of a reference average value of the tree dielectric permittivity, it is fair to observe that this is a rather challenging task. In fact, the lack of clear diffraction hyperbolas in the radargrams as well as of any reflection from the opposite side of the trunk did not allow to estimate the velocity of the electromagnetic wave from the available data.

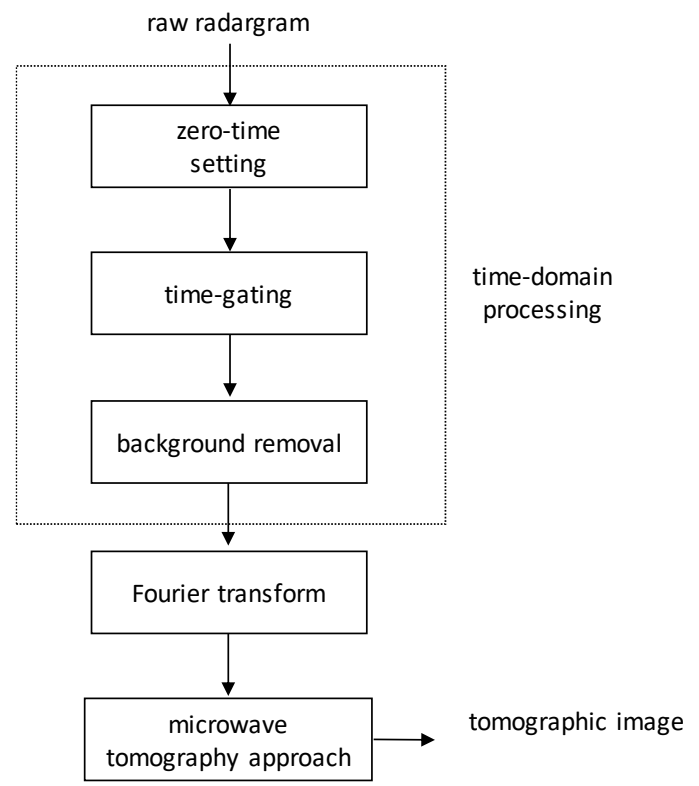

Fig. 6. Block diagram of the proposed GPR data processing framework.

Therefore, here we assume a relative permittivity of the hollow tree in the range $15-25$, based on the available literature data $[49,50]$.

Accordingly, the "blind" zone in the sapwood due to timegating operation extends from the bark up to a reference depth in the range $8-10 \mathrm{~cm}$. In view of the above, the filtered radargrams in Fig. 7 are the datasets used for the imaging in the present paper. As it is shown in Fig. 6, the radargrams are first transformed in the frequency domain by the application of a Fourier transform and, finally, they are processed using the microwave tomographic approach, as discussed in the following section.

\section{B. The Microwave Tomography Approach}

The GPR imaging is performed by means of the microwave tomography inversion approach presented in [46]. The approach exploits a linear model of the electromagnetic scattering based on the Born approximation [39, 40]. This inverse modelling allows to achieve a qualitative reconstruction of the buried targets in terms of their location and size estimation [54].

In more detail, considering the scenario under investigation and the deployed GPR system, we assume a 2D geometry with a multi-monostatic/multi-frequency configuration. The 2D geometry considers the cross-section of the tree trunk at the height where the measurement points $\boldsymbol{r}_{m}$ are located, as the investigation domain $D$. Therefore, $D$ is a trunk section at a constant height and a homogeneous medium with a constant relative dielectric permittivity $\varepsilon_{b}$ is assumed as the reference scenario.

According to the above, the measured scattered field $E_{s}$ at each measurement point $\boldsymbol{r}_{m}$ (antenna location) and angular frequency $\omega$ is given by:

$$
E_{s}\left(\boldsymbol{r}_{m}, \omega\right)=k_{b}^{2} \iint_{D} g_{e}\left(\boldsymbol{r}_{m}, \boldsymbol{r}, \omega\right) E_{i n c}(\boldsymbol{r}, \omega) \chi(\boldsymbol{r}) d \boldsymbol{r}
$$


(a)

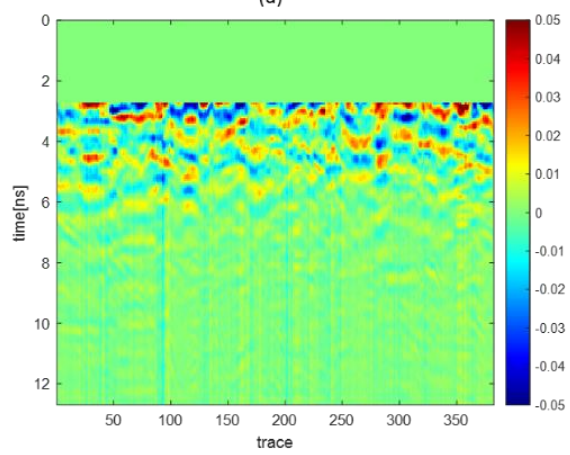

(b)

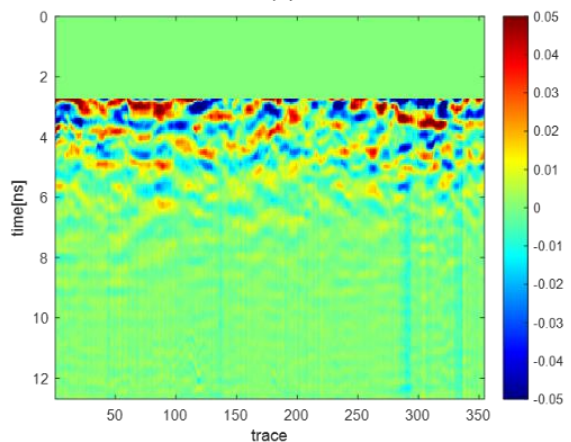

(c)

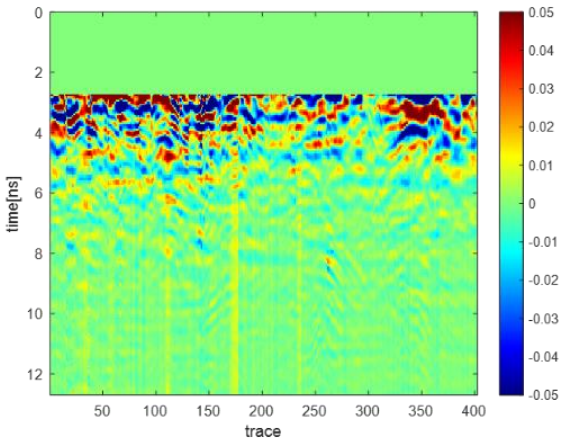

Fig. 7 Radargrams achieved after the application of the zero-time setting, time-gating and background removal. $h=0 \mathrm{~m}(\mathrm{a}), h=0.6 \mathrm{~m}(\mathrm{~b})$ and $h=1.3 \mathrm{~m}(\mathrm{c})$.

(a)

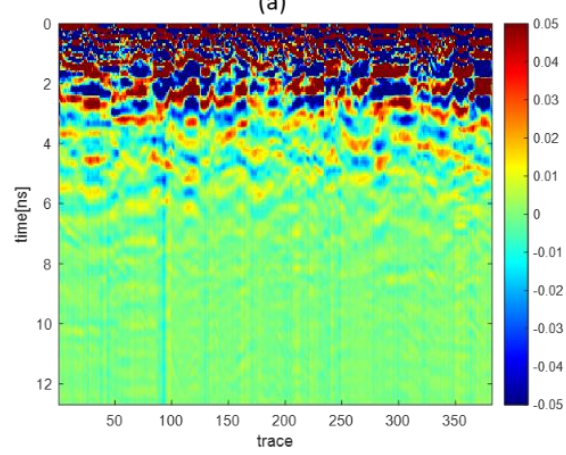

(d)

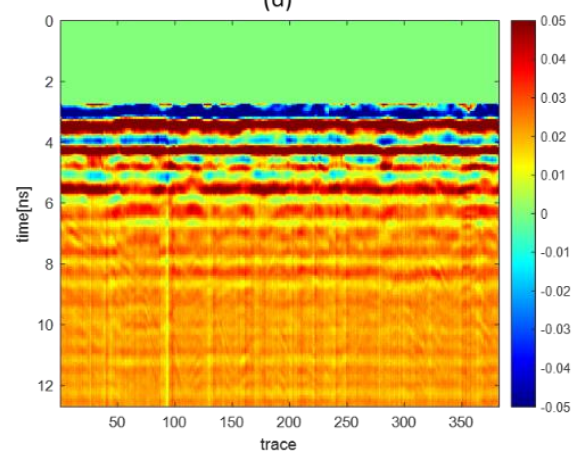

(b)

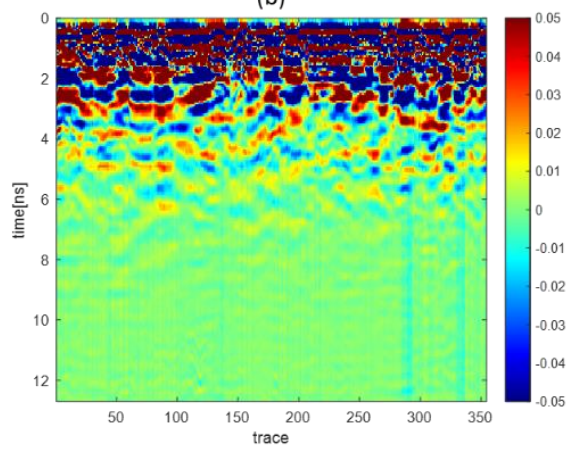

(e)

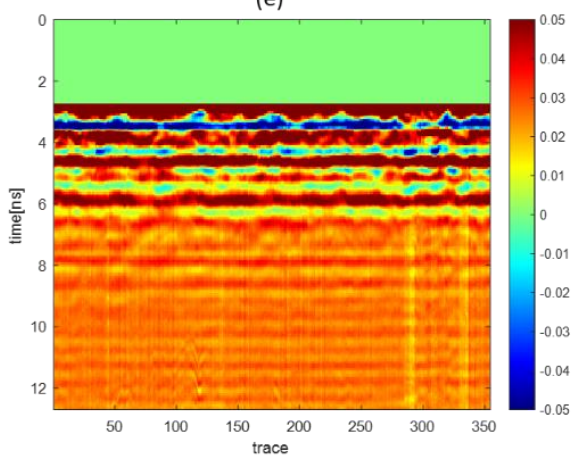

(c)

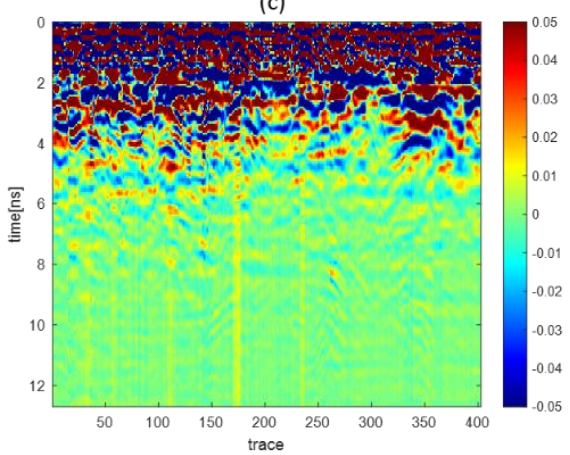

(f)

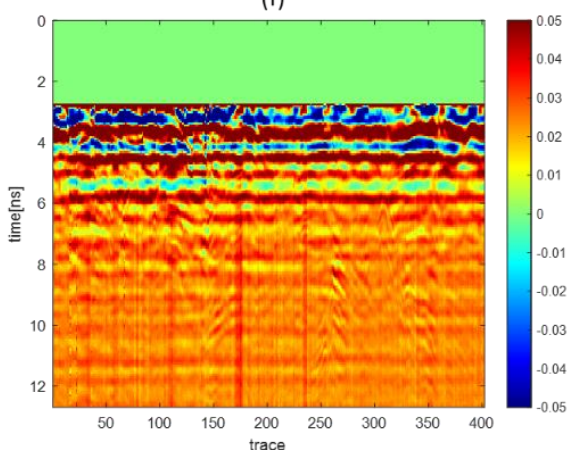

Fig. 8 Radargrams achieved after the application of the zero-time setting with background removal only (upper panels) and with time-gating only (bottom panels). $h=0 \mathrm{~m}$ (a) (d), $h=0.6 \mathrm{~m}$ (b), (e), and $h=1.3 \mathrm{~m}$ (c), (f).

where the contrast function $\chi$ accounts for the difference between the targets' permittivity and the permittivity of the background medium. $k_{b}$ is the wavenumber of the medium, $E_{i n c}$ is the incident field (i.e. the field in absence of targets) in $D$ and $g_{e}$ is the external Green's function accounting for the radiation at $\boldsymbol{r}_{m}$ by an elementary source located at $\boldsymbol{r}$. A transverse magnetic (TM) polarisation is considered where the source radiating the incident field is assumed as a filamentary electric current orthogonal to the investigation domain.

The solution to the integral equation in (1) has been largely discussed in the literature (e.g. see [39, 40]). Notably, the inverse problem in eq. (1) is ill-posed and a regularised solution is found by resorting to the Truncated Singular Value Decomposition (TSVD) scheme [53]:

$$
\tilde{\chi}(x, z)=\sum_{n=1}^{N_{t}} \frac{\left\langle E_{s}, u_{n}\right\rangle}{\sigma_{n}} v_{n}
$$

In Eq. (2), the symbol $\langle$,$\rangle is the scalar product in the data$ space, $\left\{\sigma_{n}, u_{n}, v_{n}\right\}_{n=1}^{\infty}$ is the singular spectrum of the operator
$L$, where the singular values $\sigma_{n}$ are sorted in a descending order, $\left\{u_{n}\right\}_{n=1}^{\infty}$ and $\left\{v_{n}\right\}_{n=1}^{\infty}$ are orthonormal basis functions for the data and unknown spaces, respectively. $N_{t}$ is the regularisation parameter set to find a trade-off between accuracy and stability of the solution. The modulus of the regularised contrast function $\tilde{\chi}$ is a spatial map referred to as the tomographic image.

\section{Numerical Results}

Before dealing with the processing of the experimental data, we perform a numerical analysis to test the capabilities of the microwave tomographic approach in providing useful insights for a reliable interpretation of the tomographic reconstructions in real-life scenarios. Main goals in this Section are i) to identify the presence of an inner cavity and the geometry of the sapwood (structural) layer, and ii) to verify the effects of errors in the assumption of permittivity by model compared to the actual (true) permittivity value for reconstructions with the microwave tomographic approach. 


\section{1) Detection of tree internal geometric features}

Regarding the detection of the internal geometric features of a hollow tree, it is worthy to recall the filtering properties of the linear inverse operator in eq. (1), under the reflection configuration here considered. To elaborate, a low-pass filtering along the direction of movement of the antenna and a band-pass filtering along the depth arise (see the discussion in [45]). Therefore, the tomographic images achieved by inverting eq. (1) will be able to reconstruct the fast variations of the contrast function along the depth.

In the case at hand, significant and fast variations of the relative dielectric permittivity occur at the interface between the sapwood and the cavity (i.e., the transition between the high permittivity of the sapwood and the free-space permittivity). Accordingly, the microwave tomography can detect and geometrically estimate the interface between the sapwood and the inner cavity.

The above considerations are clarified by the reconstruction performed on the simulated tree geometry represented in Fig .9. In this case scenario, the tree has a circular section with a radius of $0.8 \mathrm{~m}$ and contains a cavity with an irregular shape (dark brown area in Fig. 9). The sapwood region (yellow area in Fig. 9) is homogeneous with a relative permittivity $\varepsilon_{b}=20$ and an electric conductivity $\sigma_{b}=0.05 \mathrm{~S} / \mathrm{m}$. The tree is probed by an electric line current operating in the band [500, 2000] $\mathrm{MHz}$ and moving along the tree perimeter with a spacing of $1.1 \mathrm{~cm}$. A simulated radargram (Fig. 10a) was generated by means of the numerical solver GPRmax2D [54]. This was processed in the time-domain by setting the zero-time at $0.7 \mathrm{~ns}$ and applying a time-gating up to $1 \mathrm{~ns}$, followed by a background removal. The filtered radargram was transformed in the frequency domain over the operating band [500, 2000] $\mathrm{MHz}$ at steps of $25 \mathrm{MHz}$. A background scenario made of a homogeneous medium with relative dielectric permittivity equal to 20 has been considered for data inversion purposes. The tomographic reconstruction is achieved via TSVD with a threshold level at $-30 \mathrm{~dB}$.

The tomographic image is depicted in Fig. 10b and shows a reliable reconstruction of the interface corresponding to the transition between the sapwood and the cavity. The resolution achievable at the interface sections is related to the bandwidth of the signal and the permittivity assumed in the inverse model [51]; in the case at hand, the resolution along the depth is about $2 \mathrm{~cm}$.

\section{2) Sensitivity analysis}

This Section aims at assessing how the internal reconstruction of a typical hollow tree configuration by the tomographic inversion approach depends on the input permittivity value and changes according to its model value.

To elaborate, we verify the scale and distribution of prediction errors linked with the assumption of permittivity in the model in relationship to the actual (true) permittivity value for reconstructions achieved through the microwave tomography inversion approach. The sensitivity analysis considers the depth position of the sapwood-cavity interface as the reference parameter for the evaluation of the model errors.

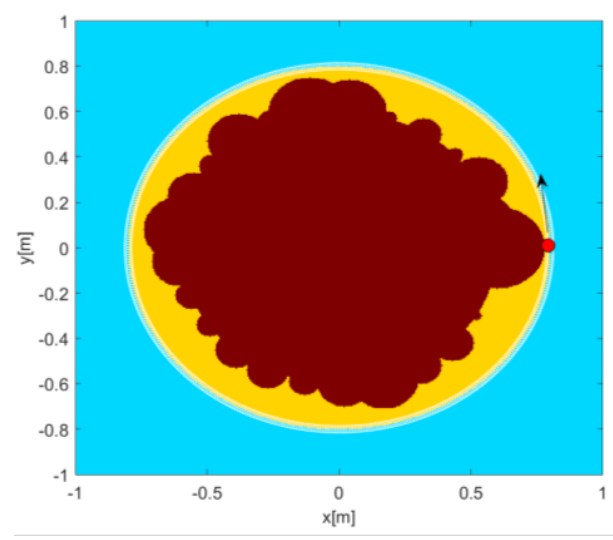

Fig. 9 Simulated tree section with an inner cavity (dark brown region). The sapwood is the region in yellow.

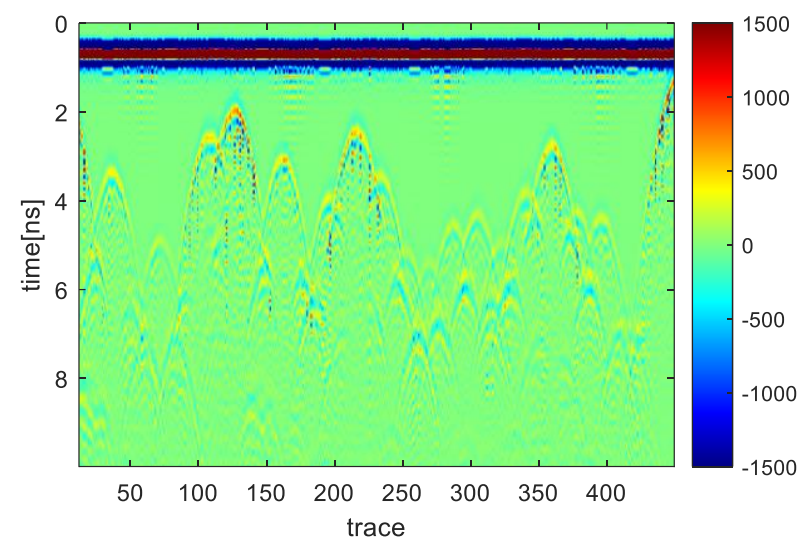

(a)

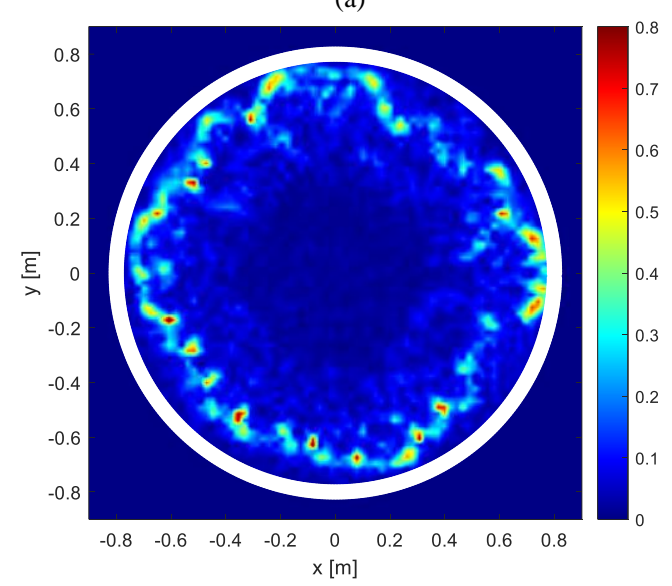

(b)

Fig. 10 Simulated radargram (a) and tomographic reconstruction (b) for the scenario depicted in Fig. 9.

To this purpose, reconstructions were performed in reference to the simulated tree section in Fig. 9, where combinations of three different values of relative dielectric permittivity, i.e., $\varepsilon=15$, 20,25 , have been considered as true permittivity $\varepsilon_{b}$ and model permittivity $\varepsilon_{m}$, case by case. These permittivity values were selected in line with the outcomes obtained in [49]. It is worth mentioning that the effect of a relative dielectric permittivity model assumption error of \pm 5 has been investigated in this sensitivity analysis. This is to effectively represent variations in water content within the sapwood layer relevant to early-stage decay conditions. 
(a)

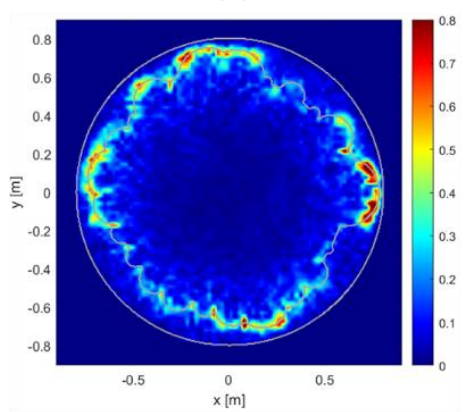

(d)

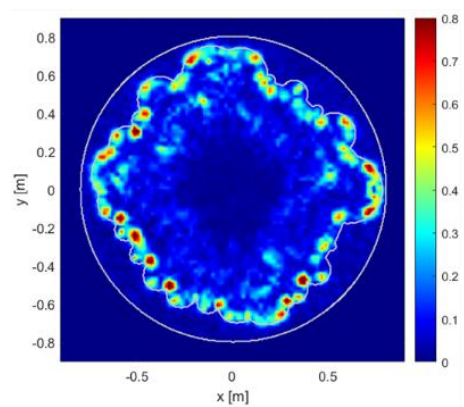

(b)

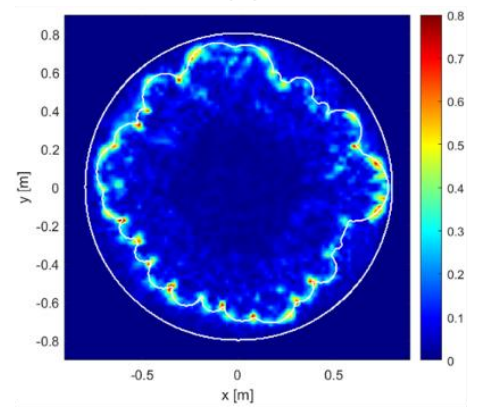

(e)

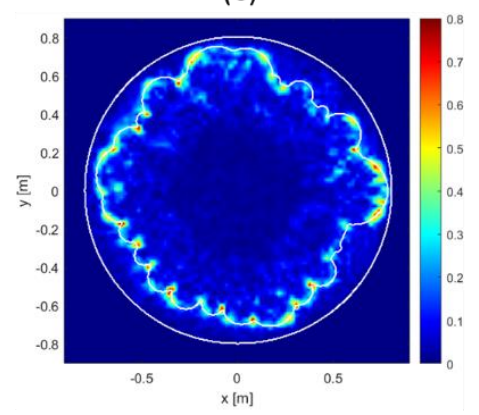

(c)

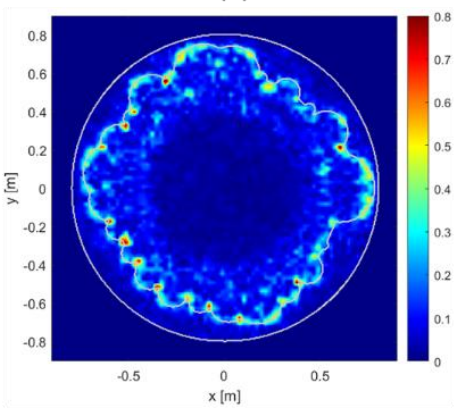

(f)

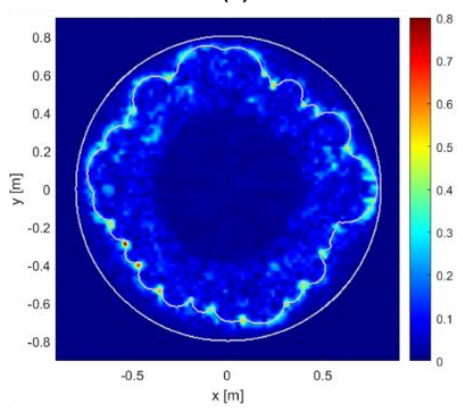

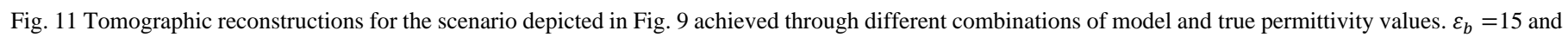
$\varepsilon_{m}=15$ (a). $\varepsilon_{b}=20$ and $\varepsilon_{m}=20$ (b). $\varepsilon_{b}=25$ and $\varepsilon_{m}=25$ (c). $\varepsilon_{b}=20$ and $\varepsilon_{m}=15$ (d). $\varepsilon_{b}=20$ and $\varepsilon_{m}=20$ (e). $\varepsilon_{b}=20$ and $\varepsilon_{m}=25$ (f).

In detail, the two following scenarios have been simulated and tomographic reconstructions were produced accordingly (Fig. 11), i.e., i) true permittivity $\varepsilon_{b}$ matching the model permittivity $\varepsilon_{m}$ (Figs. 11a-c) and ii) true permittivity ( $\varepsilon_{b}=20$ assumed as the benchmark) different from the model permittivity $\left(\varepsilon_{b}=15,25\right)$ (Figs. 11d-f). Figures 11a-c show that when $\varepsilon_{m}=\varepsilon_{b}$, the reconstructed contrast function perfectly matches the sapwood-cavity interface geometry, with enhancements in the image resolution observed in case of higher permittivity values. Conversely, when permittivity values assumed in the inverse model differ from the true permittivity, an error occurs in the prediction of the true depth position of the sapwood-cavity interface. This is shown in Fig. $11 \mathrm{~d}$ and Fig. 11f, where the true permittivity $\varepsilon_{b}=20$ is underestimated and overestimated, respectively, as opposed to the image reconstruction in Fig. 11e $\left(\varepsilon_{m}=\varepsilon_{b}=20\right)$, where no prediction errors occur.

To quantify the model prediction errors on the sapwoodcavity interface in Figs. 11d-f, the theory discussed in [55] is here used. To elaborate, when the assumed (model) permittivity $\varepsilon_{m}$ is smaller (or larger) than the actual (true) value of the permittivity $\varepsilon_{b}$, the modelled target depth $z_{m}$ is larger (or smaller) than the true depth $z_{b}$, according to the following equation:

$$
z_{m}=\sqrt{\frac{\varepsilon_{b}}{\varepsilon_{m}}} z_{b}
$$

The model error $\psi$ can be therefore worked out from eq. (3) as the absolute difference between the estimated target depth $z_{m}$ and the true depth $z_{b}$, as follows:

$$
\chi=\left|z_{m}-z_{b}\right|=\left|1-\sqrt{\frac{\varepsilon_{b}}{\varepsilon_{m}}}\right| z_{b}
$$

Figure 12 reports the distribution of the model errors along the actual air-sapwood interface in reference to the tomographic reconstructions in Figs. 11d-f.

Being constant the difference between model and true permittivity for the combinations $\varepsilon_{b}=20$ and $\varepsilon_{m}=15$ (Fig. 11d), $\varepsilon_{b}=20$ and $\varepsilon_{m}=25$ (Fig. 11f), it is observed that the scale of the errors is higher when the true permittivity is underestimated. This behaviour is consistent with eq. (4) that indicates how the model error depends on the ratio between the true and the model permittivity. Underestimation of the true permittivity is also confirmed by the statistics reported in Table II, where the absolute mean error $\bar{\psi}$ for $\varepsilon_{m}=15$ and $\varepsilon_{m}=25$ is $0.96 \mathrm{~cm}$ and $0.66 \mathrm{~cm}$, respectively. In addition, it is important to observe that a maximum error $\sim 3 \mathrm{~cm}$ is expected in case similar permittivity values are considered for the estimation of the sapwood-cavity interface position in hollow trees.

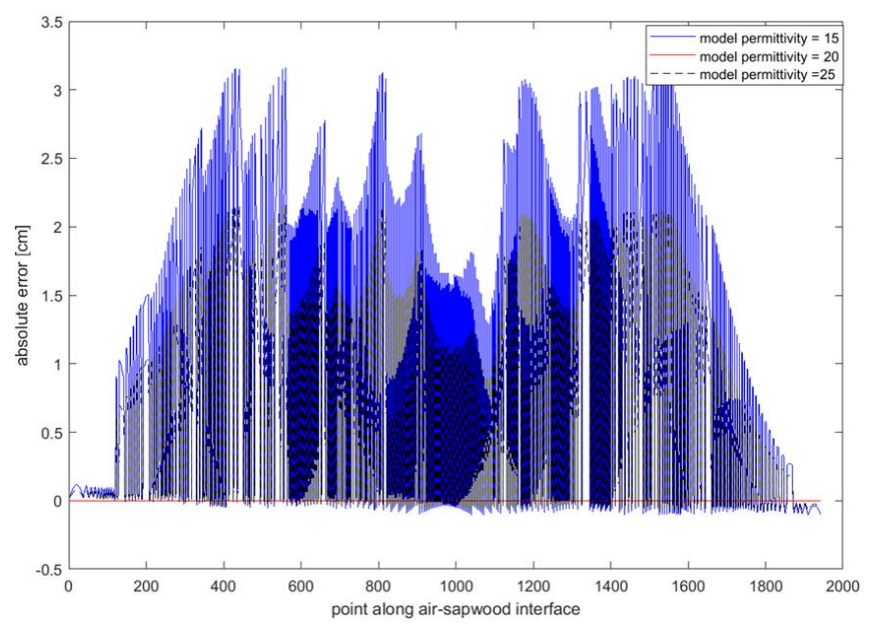

Fig. 12 Error distribution along the sapwood-cavity interface for the tomographic reconstructions in Figs. 11d-f. 
TABLE II

MAIN STATISTICS FOR THE DISTRIBUTION OF THE MODEL ERROR ALONG THE SAPWOOD-CAVITY INTERFACE IN FIGS. 11D-F

\begin{tabular}{cccc}
\hline \hline $\begin{array}{c}\text { Model Permittivity } \\
\varepsilon_{m}[-]\end{array}$ & $\begin{array}{c}\bar{\psi} \\
{[\mathrm{cm}]}\end{array}$ & $\begin{array}{c}\max \psi \\
{[\mathrm{cm}]}\end{array}$ & $\begin{array}{c}\min \psi \\
{[\mathrm{cm}]}\end{array}$ \\
\hline 15 & 0.96 & 3.16 & 0.11 \\
20 & 0 & 0 & 0 \\
25 & 0.66 & 2.16 & 0.07 \\
\hline \hline
\end{tabular}

\section{REAL RECONSTRUCTIONS: RESULTS AND DISCUSSION}

In this Section, we show the reconstruction results of the real tree sections in Fig. 3 achieved by the application of the data processing framework represented in Fig. 6. To this end, the filtered radargrams in Fig. 7 are transformed into the frequency domain over the interval 500-2000 MHz with steps of $25 \mathrm{MHz}$.

For the data inversion, the measurement points are defined to account for the exact positions of the antenna along the tree trunk perimeter. These positions are determined using the arc length parameterisation approach, as described in [35]. The shape of the trunk is initially discretised $\{x, y \in \mathbb{R} \mid x, y>0\}$, where the vectors $\mathbf{x} \in \mathbb{R}^{\mathbf{n}}$ and $\mathbf{y} \in \mathbb{R}^{\mathrm{n}}$ contain the $n$ distinct coordinates around the investigated trunk. Subsequently, the vector $\theta \in \mathbb{R}^{\mathrm{n}}$ is defined with $n$ equidistant points from zero to one. A spline interpolation is used to map both $\mathbf{x}$ and $\mathbf{y}$ with respect to $\boldsymbol{\theta}$ i.e., $\mathbf{F}=\langle\mathrm{P}(\theta), \mathrm{Q}(\theta)\rangle$, where $\mathrm{P}(\theta)$ and $\mathrm{Q}(\theta)$ are the continuous representation of the $x, y$ coordinates respectively.

The arc length of the curve $\mathbf{F}$ is then evaluated using $s(\tau)=\int_{0}^{\tau}\left\|\frac{d \mathbf{F}}{d \theta}\right\| d \theta$. The latter integral is calculated numerically for different $\tau$. The values of $\tau$ are then expressed analytically with respect to $s(\tau)$ using a spline interpolation. Therefore, for a given distance $s(\tau)$ we can derive the parametric variable $\tau$. Knowing the parametric variable $\tau$ associated with a specific distance, allow us to calculate the coordinates $\mathbf{F}=\langle\mathrm{P}(\tau), \mathrm{Q}(\tau)\rangle$ subject to the distance measured using the wheel-measuring device available in most commercial GPR systems.

The investigation domain matches with the actual tree crosssection and it is discretised into square image pixels with size 1 $\mathrm{cm}$. The reconstruction results presented in this paper are achieved by considering three different values of relative dielectric permittivity, i.e., $\varepsilon_{b}=15,20,25$, for the cross-section reference scenarios at $h=0 \mathrm{~m}$ (Fig. 13), $h=0.6 \mathrm{~m}$ (Fig. 14) and $h=1.3 \mathrm{~m}$ (Fig. 14), for consistency with the permittivity values used in the numerical simulations and in line with the outcomes obtained in [49].

To allow a quantitative analysis of the viability of the microwave tomography inversion approach in estimating the thickness of the sapwood structural layer, the tomographic reconstructions in Figs. 13-15 were converted into binary images, and subsequently a spline interpolation was applied to reconstruct the inner sapwood-cavity interface in a continuous manner (Fig. 16). The main outcomes from the evaluation of the sapwood-cavity interface in the binary tomographic images are listed in Table III in terms of the average thickness of the sapwood $\bar{R}-\bar{r}$, the hollow area $A_{H}$ and the sapwood area $A_{S}$. These are reported by considering the three values of relative dielectric permittivity, i.e., $\varepsilon_{b}=15,20,25$ for all the three cross-section reference scenarios at $h=0 \mathrm{~m}, h=0.6 \mathrm{~m}$ and $h=$ $1.3 \mathrm{~m}$. For comparison purposes, the absolute errors $\Delta$ between reconstructed and real scenarios and the absolute percentage errors $\xi, \kappa$ and $\varsigma$ are reported for $\bar{R}-\bar{r}, A_{H}$ and $A_{S}$, respectively.

Regarding the bottom cross-section at $h=0 \mathrm{~m}$, the tomographic images displayed in the top panels of Fig. 13 show that the sapwood-cavity interface is clearly identified in all the three cases of considered background relative dielectric permittivity. This agrees with the tomographic reconstruction obtained in the simulated scenario (Fig. 10). Moreover, higher reference permittivity values produce a slight resolution enhancement in the tomographic images and the reconstruction of the interface is closer to the outer surface due to the smaller propagation velocity in the assumed model, as observed in Fig. $11 \mathrm{~d}$.

The bottom panels of Fig. 13 show the tomographic images with the actual cross-sections superimposed. It can be noted that the use of $\varepsilon_{b}=25$ allows to achieve the best reconstruction of the sapwood-cavity interface in terms of accuracy of the localisation and the spatial resolution. This claim is confirmed by the analysis of the corresponding binary images at crosssection $h=0 \mathrm{~m}$ in Figs. 16a-c, where the best interface reconstruction is achieved for $\varepsilon_{b}=25$, despite of slightly lower percentage errors $\xi, \kappa$ and $\varsigma$ obtained when $\varepsilon_{b}=20$. Predictions from the application of the tomographic inversion approach return an average sapwood thickness of $20.95 \mathrm{~cm}$ and $19.10 \mathrm{~cm}$ when $\varepsilon_{b}=20$ and $\varepsilon_{b}=25$, respectively, compared to the real-truth thickness of $20.17 \mathrm{~cm}$.

The tomographic images in Fig. 14 refer to the cross-section at $h=0.6 \mathrm{~m}$. The interface between the sapwood and the cavity is clearly visible, and the permittivity value $\varepsilon_{b}=25$ provides the best reconstruction in terms of localisation accuracy and the resolution of the sapwood-cavity interface. This can be verified from the corresponding binary images in Figs. 16d-f (crosssection $h=0.60 \mathrm{~m}$ ), where the best matching is again observed when $\varepsilon_{b}=25$. The accuracy of the algorithm in the case of the highest background permittivity is further confirmed by the very high prediction accuracy in absolute values for the sapwood thickness (i.e., $16.50 \mathrm{~cm}$ against $16.65 \mathrm{~cm}$ for the ground-truth value), the hollow area $A_{H}\left(5912.08 \mathrm{~cm}^{2}\right.$ against a ground-truth reference of $5871 \mathrm{~cm}^{2}$ ), and the sapwood area $A_{S}$ $\left(5352.44 \mathrm{~cm}^{2}\right.$ against a ground-truth reference of $\left.5393.52 \mathrm{~cm}^{2}\right)$. These values return the lowest percentage errors $(<1 \%)$ observed across the three analysed parameters, as opposed to the predictions achieved when $\varepsilon_{b}=15$ and $\varepsilon_{b}=20$ (Table III).

Figure 15 displays the tomographic images relevant to the top section at $h=1.3 \mathrm{~m}$. In this scenario, the permittivity values $\varepsilon_{b}=20$ and $\varepsilon_{b}=25$ provide a similar qualitative reconstruction of the interface in terms of the accuracy of the location, whereas an improved resolution is reached when $\varepsilon_{b}=25$. However, the analysis of the corresponding binary images in Figs. 16g-i (cross-section $h=1.30 \mathrm{~m}$ ) shows that the best localisation of the interface is again achieved with a medium permittivity $\varepsilon_{b}=25$. 
(a)
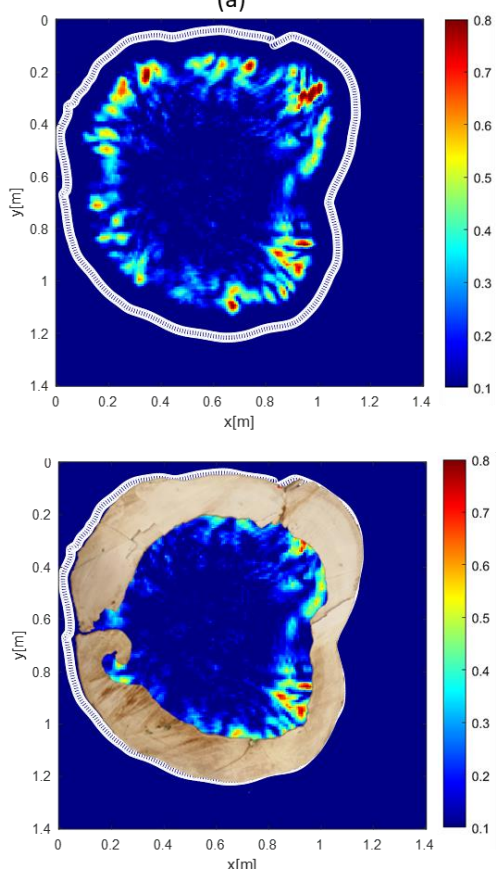

(b)
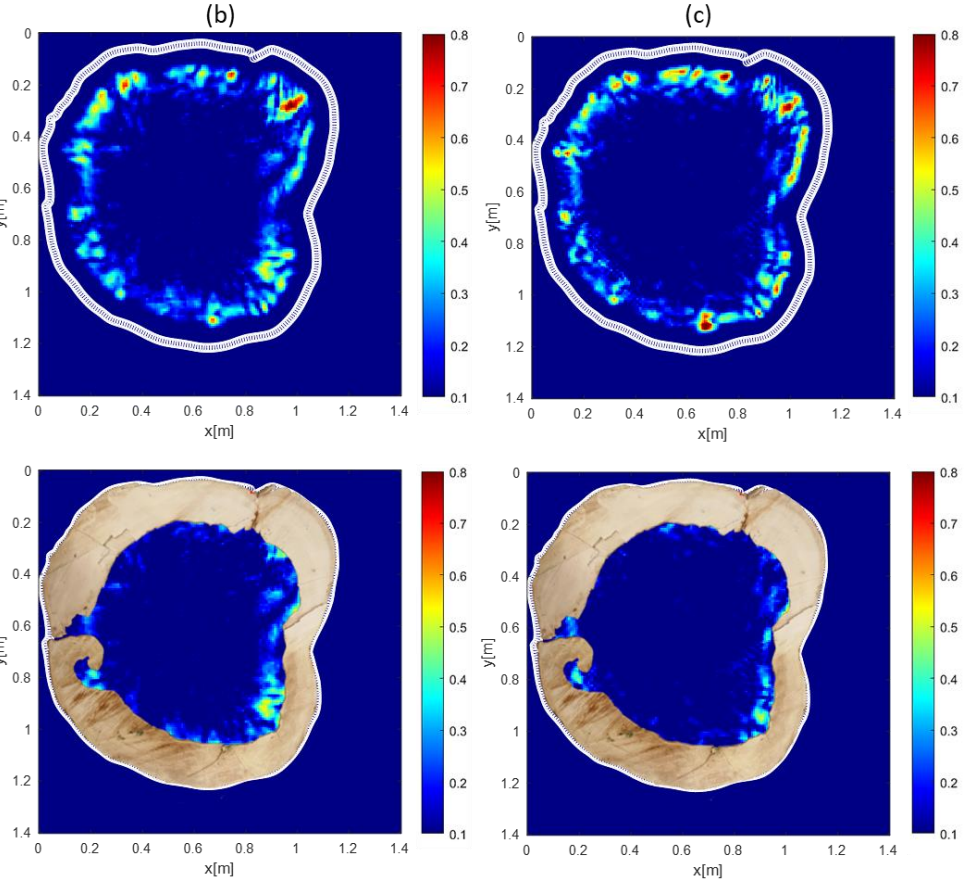

Fig. 13. Tomographic images (upper panels) and tomographic images with the actual cross-sections superimposed (lower panels) for the tree section at $h=0 \mathrm{~m}$ and three increasing values (from left to right) of the background relative dielectric permittivity. $\varepsilon_{b}=15$ (a). $\varepsilon_{b}=20$ (b). $\varepsilon_{b}=25$ (c). Colour scale [0.1, 0.8].
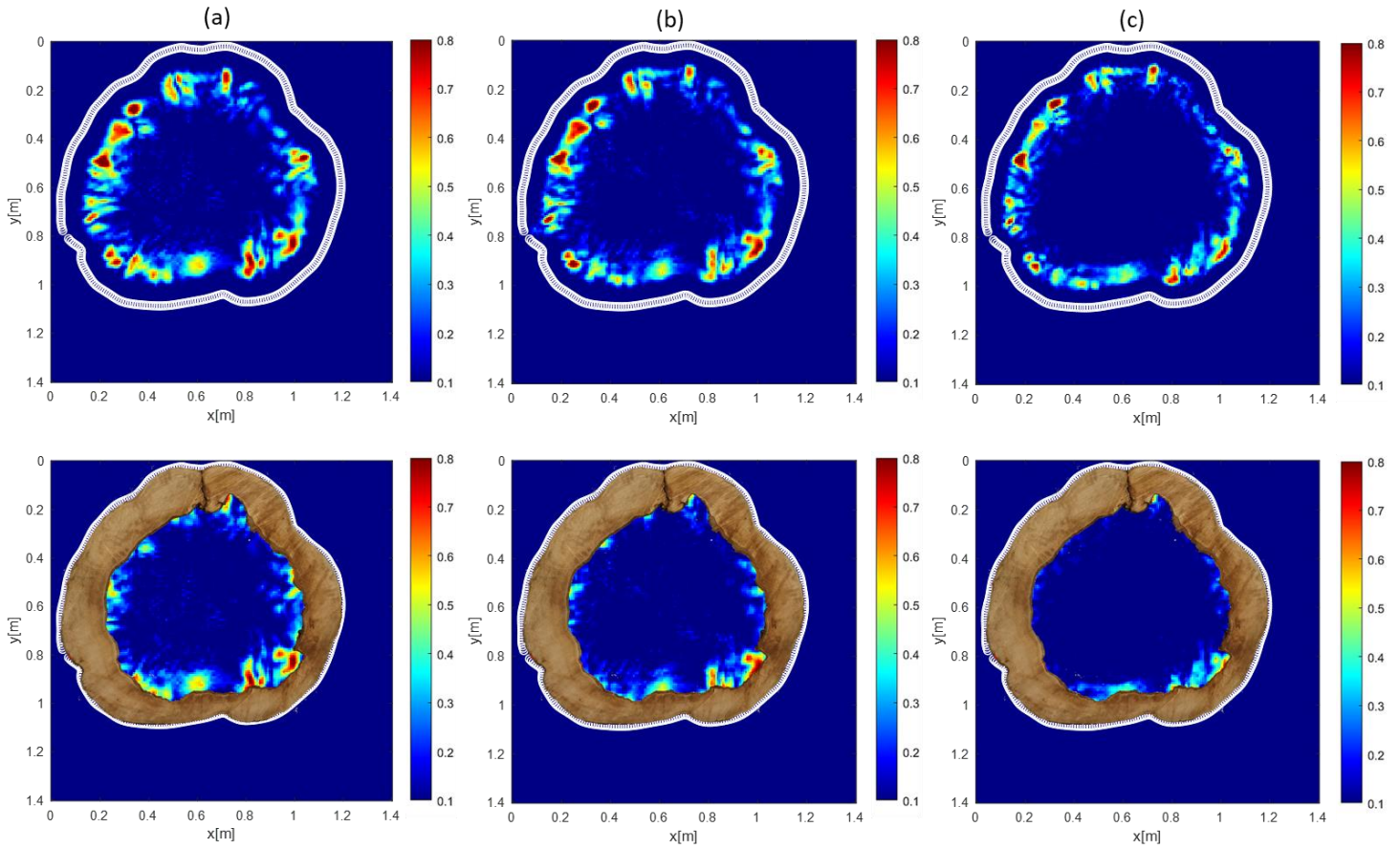

Fig. 14. Tomographic images (upper panels) and tomographic images with the actual cross-sections superimposed (lower panels) for the tree section at $h=0.6 \mathrm{~m}$ and three increasing values (from left to right) of the background relative dielectric permittivity. $\varepsilon_{b}=15$ (a). $\varepsilon_{b}=20$ (b). $\varepsilon_{b}=25$ (c). Colour scale [0.1, 0.8$]$. 
(a)
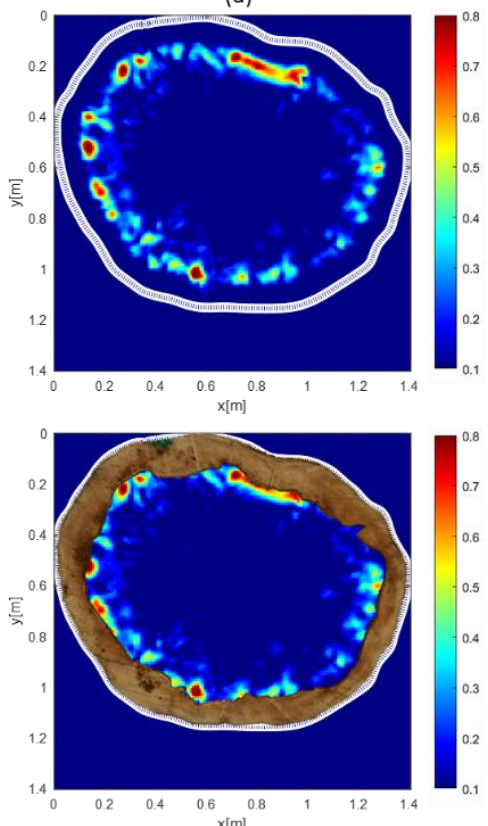

(b)
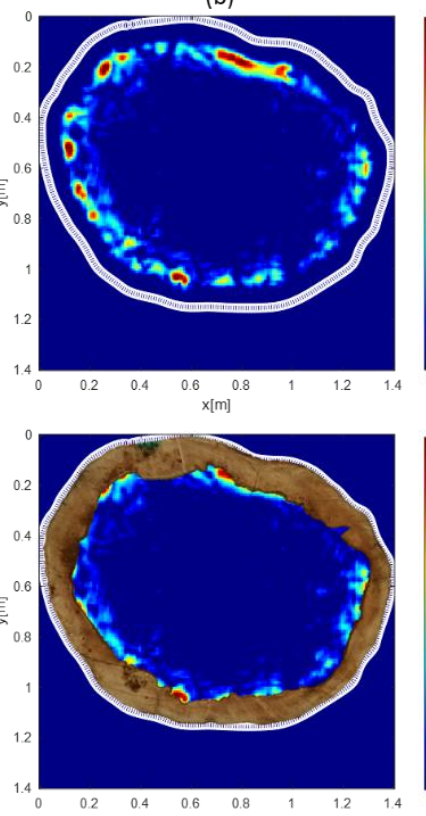
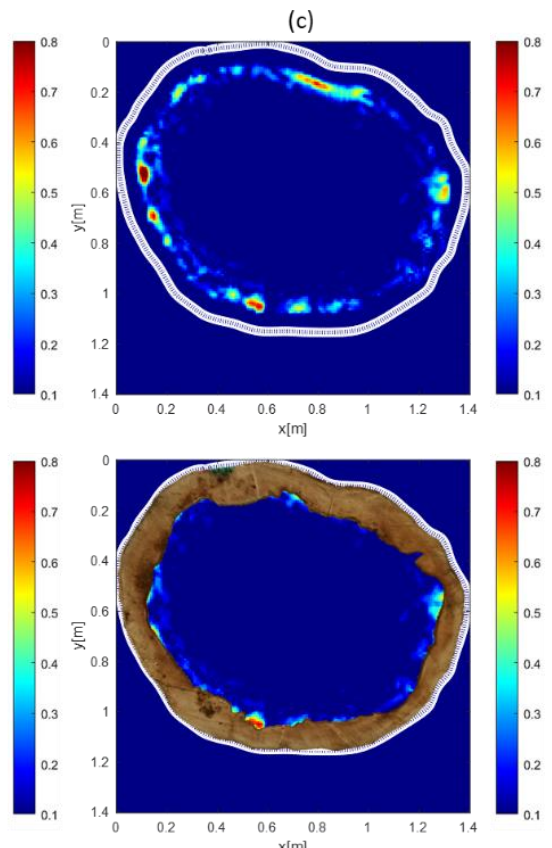

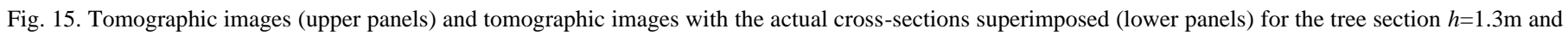
three increasing values (from left to right) of the background relative dielectric permittivity. $\varepsilon_{b}=15$ (a). $\varepsilon_{b}=20$ (b). $\varepsilon_{b}=25$ (c). Colour scale [0.1, 0.8$]$.
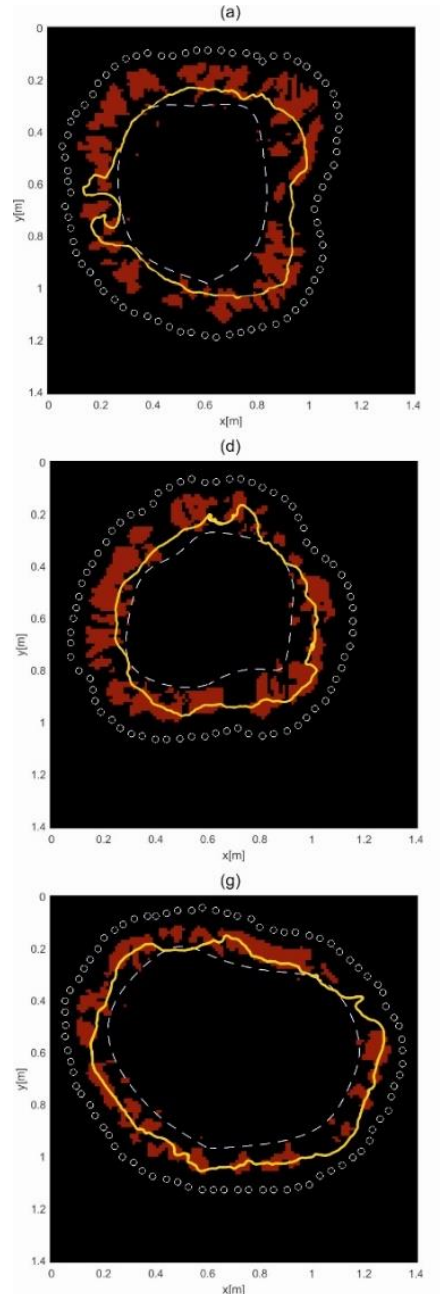
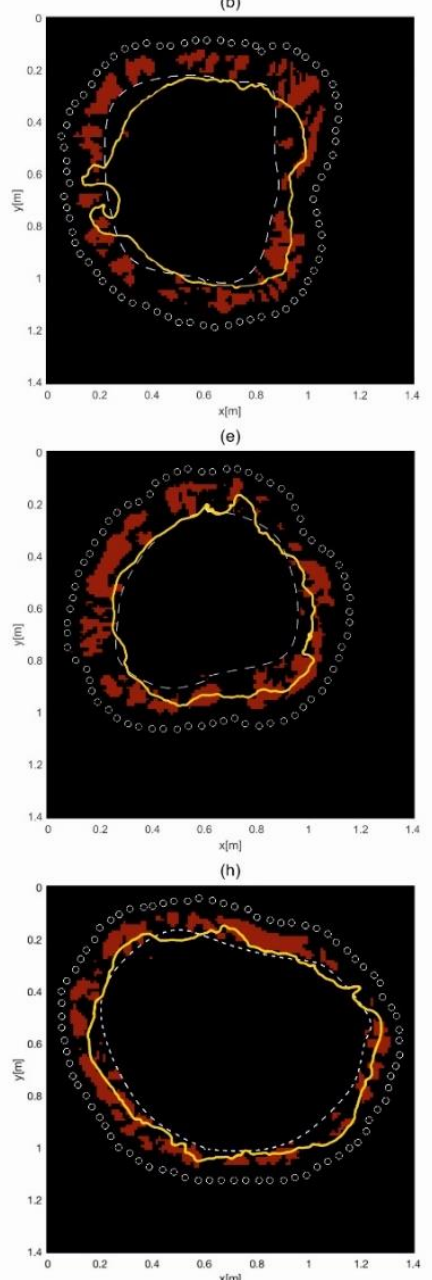
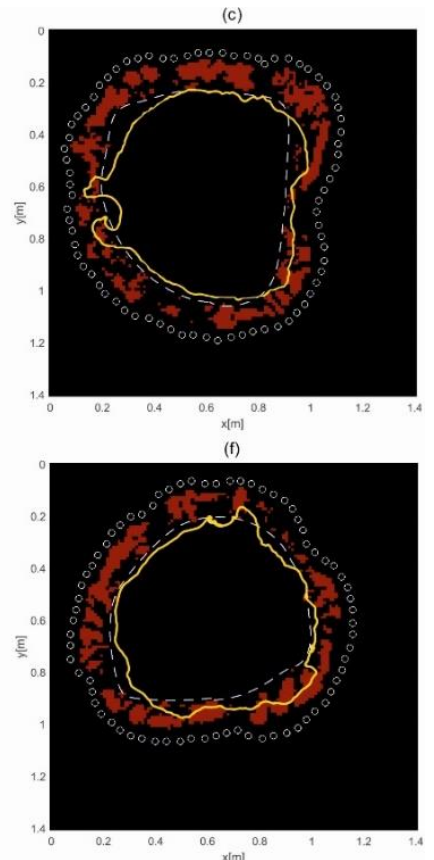

(i)

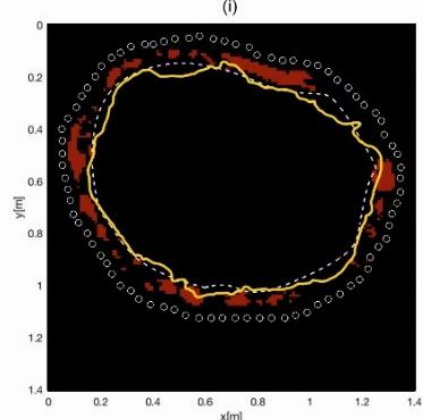

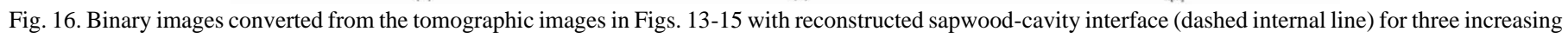

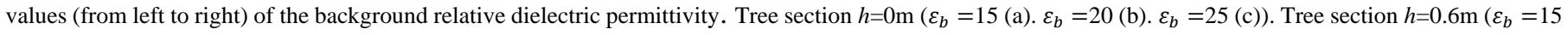

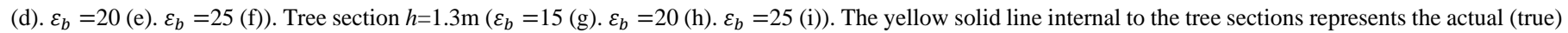
sapwood-cavity interface. 
TABLE III

REAL VS PERMITTIVITY-BASED MODELLED VALUES OF MAIN TREE GEOMETRIC PARAMETERS FROM THE INVESTIGATED CROSS-SECTIONS AND ABSOLUTE AND PERCENTAGE PREDICTION ERRORS BASED ON DATA ANALYSIS OF THE BINARY TOMOGRAPHIC IMAGES IN FIG. 16. REAL PARAMETER VALUES ARE IN BOLD

\begin{tabular}{|c|c|c|c|c|c|c|c|c|c|c|c|}
\hline Section & & $\begin{array}{c}\bar{R} \\
{[\mathrm{~cm}]}\end{array}$ & $\begin{array}{c}\bar{R}-\bar{r} \\
{[\mathrm{~cm}]}\end{array}$ & $\begin{array}{c}\Delta \\
{[\mathrm{cm}]}\end{array}$ & $\begin{array}{c}\xi \\
{[\%]}\end{array}$ & $\begin{array}{c}\text { Hollow Area } \\
A_{H} \\
{\left[\mathrm{~cm}^{2}\right]} \\
\end{array}$ & $\begin{array}{c}\Delta \\
{\left[\mathrm{cm}^{2}\right]}\end{array}$ & $\begin{array}{c}\kappa \\
{[\%]}\end{array}$ & $\begin{array}{c}\text { Sapwood Area } \\
A_{S} \\
{\left[\mathrm{~cm}^{2}\right]} \\
\end{array}$ & $\begin{array}{c}\Delta \\
{\left[\mathrm{cm}^{2}\right]}\end{array}$ & $\begin{array}{c}\Sigma \\
{[\%]}\end{array}$ \\
\hline \multirow{4}{*}{$\begin{array}{c}\mathrm{P}_{1} \\
(h=0 \mathrm{~m})\end{array}$} & Real & \multirow{4}{*}{69.31} & 20.17 & - & - & 7585.85 & - & - & 7505.22 & - & - \\
\hline & $\varepsilon=15$ & & 28.22 & 8.05 & 39.91 & 5304.07 & 2281.78 & 30.08 & 9787.00 & 2281.78 & 30.40 \\
\hline & $\varepsilon=20$ & & 20.95 & 0.78 & 3.87 & 7347.00 & 238.85 & 3.15 & 7744.07 & 238.85 & 3.18 \\
\hline & $\varepsilon=25$ & & 19.10 & 1.07 & 5.32 & 7920.91 & 335.06 & 4.42 & 7170.16 & 335.06 & 4.46 \\
\hline \multirow{2}{*}{$\mathrm{P}_{2}$} & Real & \multirow{4}{*}{59.88} & 16.65 & - & - & 5871.00 & & - & 5393.52 & - & - \\
\hline & $\varepsilon=15$ & & 23.51 & 6.86 & 41.18 & 4156.26 & 1714.74 & 29.21 & 7108.26 & 1714.74 & 31.79 \\
\hline \multirow[b]{2}{*}{$(h=0.6 \mathrm{~m})$} & $\varepsilon=20$ & & 22.59 & 5.94 & 35.68 & 4368.41 & 1502.59 & 25.59 & 6896.11 & 1502.59 & 27.86 \\
\hline & $\varepsilon=25$ & & 16.50 & 0.15 & 0.91 & 5912.08 & 41.08 & 0.70 & 5352.44 & 41.08 & 0.76 \\
\hline \multirow{2}{*}{$\mathrm{P}_{3}$} & Real & \multirow{4}{*}{62.33} & 11.63 & - & - & 8075.95 & - & - & 4129.68 & - & - \\
\hline & $\varepsilon=15$ & & 17.84 & 6.21 & 53.38 & 6219.48 & 1856.47 & 22.99 & 5986.15 & 1856.47 & 44.95 \\
\hline \multirow[b]{2}{*}{$(h=1.3 \mathrm{~m})$} & $\varepsilon=20$ & & 14.21 & 2.58 & 22.15 & 7276.22 & 799.73 & 9.90 & 4929.41 & 799.73 & 19.37 \\
\hline & $\varepsilon=25$ & & 11.09 & 0.54 & 4.64 & 8248.63 & 172.68 & 2.14 & 3957.00 & 172.68 & 4.18 \\
\hline
\end{tabular}

This is further confirmed by the very close prediction in the absolute value of the average sapwood thickness for this crosssection (i.e., $11.09 \mathrm{~cm}$ ) compared to the ground-truth evidence of $11.63 \mathrm{~cm}$. In general, the model percentage errors in Table III indicate that a medium permittivity $\varepsilon_{b}=25$ provides the lowest errors $(<5 \%)$ against the real values of the three analysed parameters, compared to $\varepsilon_{b}=15$ and $\varepsilon_{b}=20$.

\section{CONCLUSIONS AND Future PROSPECTS}

This study reports a demonstration of the GPR capability enhanced by a microwave tomographic inversion approach in detecting hollows and cavities in tree trunks. The data collection methodology as well as the hand-held GPR antenna system and the central frequency $(2 \mathrm{GHz})$ used for the measurements on a living tree have proven viable for the inspection of hollow trees. The application of a tomographic inversion approach has demonstrated to be effective in detecting the main structural features of a hollow tree, in terms of the sapwood-cavity interface location, the sapwood layer thickness and its cross-section surface, with a centimetre prediction accuracy. However, it is observed that the provision of a dedicated data processing framework and, more specifically, clutter mitigation strategies are crucial to achieve reliable tree section images in hollow trees.

Future research could task itself on the use of reflectionbased methods for the estimation of the tree permittivity, to address lack of source of information such as clear reflection hyperbolas and localised targets, i.e., a very common condition in hollow trees. In addition, an investigation into the use of multi-frequency GPR data collected on different species and size of hollow tree trunks could allow to explore the significance of using a higher amount of information, in terms of both the GPR datasets and the physical configuration of the trees. Studying these factors can contribute to expand the application of the proposed methodology to other hollow tree types. Moreover, the use of a GPR antenna system designed on purpose for the investigation of high dielectric media, such as the internal layers of living trees, may allow for the collection of data with minimum ringing effects due to the antenna mismatch with the bark surface.
Additional future developments could be focused on the use of integrated non-destructive testing (NDT) methods, such as laser scanners, GPS and accelerometers, to allow for accurate and automatic reconstructions of the tree trunk outer surface. Finally, the investigation of new data collection and processing strategies can be explored with the aim to achieve pseudo or full $3 \mathrm{D}$ representations of the internal structure of trees following the approaches presented in $[56,57]$.

\section{ACKNOWLEDGMENTS}

This research was funded by the following trusts, charities, organisations and individuals for their generosity in supporting this project: Lord Faringdon Charitable Trust, The Schroder Foundation, Cazenove Charitable Trust, Ernest Cook Trust, Sir Henry Keswick, Ian Bond, P. F. Charitable Trust, Prospect Investment Management Limited, The Adrian Swire Charitable Trust, The John Swire 1989 Charitable Trust, The Sackler Trust, The Tanlaw Foundation, and The Wyfold Charitable Trust. The authors would like to express their sincere thanks to Mr. Dale Mortimer (representing the Ealing Council) and the Gunnersbury Park for facilitating this research.

\section{REFERENCES}

[1] P.K. Anderson, A.A. Cunningham, N.G. Patel, F.J. Morales, P.R. Epstein and P. Daszak, "Emerging infectious diseases of plants: pathogen pollution, climate change and agrotechnology drivers," Trends in Ecology \& Evolution (Amsterdam), vol. 19, pp. 535-544, 2004.

[2] A. Santiniet al., "Biogeographical patterns and determinants of invasion by forest pathogens in Europe," The New Phytologist, vol. 197, pp. 238-250, 2013.

[3] T. Jung, "Beech decline in Central Europe driven by the interaction between Phytophthora infections and climatic extremes," Forest Pathology, vol. 39, pp. 73-94, Apr. 2009.

[4] Q. Guo, M. Rejmanek and J. Wen, "Geographical, socioeconomic, and ecological determinants of exotic plant naturalization in the United States: insights and updates from improved data," NeoBiota, vol. 12, pp. 41-55, Feb. 2012.

[5] A.M. Liebhold, E.G. Brockerhoff, L.J. Garrett, J.L. Parke and K.O. Britton, "Live plant imports: the major pathway for forest insect and pathogen invasions of the US," Frontiers in Ecology and the Environment, vol. 10, pp. 135-143, Apr. 2012.

[6] A. Broome, D. Ray, R. Mitchell and R. Harmer, "Responding to ash dieback (Hymenoscyphus fraxineus) in the UK: woodland composition and replacement tree species," Forestry: An International Journal of Forest Research, vol. 92, pp. 108-119, Jan. 2019. 
[7] M.C. Fisher, D.A. Henk, C.J. Briggs, J.S. Brownstein, L.C. Madoff, S.L. McCraw and S.J. Gurr, "Emerging fungal threats to animal, plant and ecosystem health," Nature (London), vol. 484, pp. 186-194, 2012.

[8] C. Potter, T. Harwood, J. Knight and I. Tomlinson, "Learning from history, predicting the future: the UK Dutch elm disease outbreak in relation to contemporary tree disease threats," Philosophical Transactions. Biological Sciences, vol. 366, pp. 1966-1974, July 2011.

[9] F.F.P. Kollmann and W.A. Côté, Principles of Wood Science and Technology, Berlin, Heidelberg: Springer Berlin Heidelberg, 1968.

[10] J.D. Mauseth, Botany, Burlington, Mass: Jones\& Bartlett Learning, 2014,

[11]S.G. Pallardy, Physiology of woody plants, Academic Press, 2010,

[12]Z. Zheng, S. Zhang, C. Baskin, J. Baskin, D. Schaefer, X. Yang and L. Yang, "Hollows in living trees develop slowly but considerably influence the estimate of forest biomass," Functional Ecology, vol. 30, pp. 830-838, 2016.

[13]A. Sæbø, T. Benedikz and T.B. Randrup, "Selection of trees for urban forestry in the Nordic countries," Urban Forestry \& Urban Greening, vol. 2, pp. 101-114, 2003.

[14]J.T. Basham, H.M. Good and S.D. Kadzielawa, "Respiratory activity of fungal associations in zones of heart rot and stain in sugar maple," Canadian Journal of Botany, vol. 46, pp. 27-36, 1968.

[15]S. S. Lee and Noraini Sikin Yahya, "Fungi Associated with Heart Rot of Acacia Mangium Trees in Peninsular Malaysia and East Kalimantan," Journal of Tropical Forest Science, vol. 11, pp. 240-254, Jan. 1999.

[16] K.L. Cockle, K. Martin and G. Robledo, "Linking fungi, trees, and holeusing birds in a Neotropical tree-cavity network: Pathways of cavity production and implications for conservation," Forest Ecology and Management, vol. 264, pp. 210-219, 2012.

[17]D.B. Clark and D.A. Clark, "Landscape-scale variation in forest structure and biomass in a tropical rain forest," Forest Ecology and Management, vol. 137, pp. 185-198, 2000.

[18] A.B. Edworthy and K. Martin, "Long-term dynamics of the characteristics of tree cavities used for nesting by vertebrates," Forest Ecology and Management, vol. 334, pp. 122-128, Dec. 2014

[19]C. Mattheck, K. Bethge and P.W. West, "Breakage of hollow tree stems," Trees (Berlin, West), vol. 9, Nov. 1994

[20] S. Denman, N. Brown, S. Kirk, M. Jeger and J. Webber, "A description of the symptoms of Acute Oak Decline in Britain and a comparative review on causes of similar disorders on oak in Europe," Forestry (London), vol. 87, pp. 535-551, 2014.

[21]D. Ouis, "Non Destructive Techniques for Detecting Decay in Standing Trees," Arboricultural Journal, vol. 27, pp. 159-177, Oct. 2003.

[22]P.M. Winistorfer, W. Xu and R. Wimmer, "Application of a drill resistance technique for density profile measurement in wood composite panels," Forest Products Journal, vol. 45, pp. 90, Jun. 1995.

[23]F.W.M.R. Schwarze and D. Ferner, " Ganoderma on trees-Differentiation of species and studies of invasiveness," Arboricultural Journal, vol. 27, pp. 59-77, Jun. 2003.

[24] W.C. Shortle and K.R. Dudzik, Wood Decay in Living and Dead Trees: A Pictorial Overview, U.S. Forest Service, 2015.

[25]L. Costello and S. Quarles, "Detection of wood decay in blue gum and elm: An evaluation of the Resistograph and the portable drill," Journal of Arboricoulture, pp. 311-317, 1999.

[26] S.A. al Hagrey, "Electrical resistivity imaging of tree trunks," Near Surface Geophysics, vol. 4, pp. 179-187, Jun. 2006.

[27]G. Deflorio, S. Fink and Schwarze, Francis W. M. R, "Detection of incipient decay in tree stems with sonic tomography after wounding and fungal inoculation," Wood Sci. Technol., vol. 42, pp. 117-132, 2007.

[28] A. Catena, "Thermography shows damaged tissue and cavities present in trees," Nondestructive Characterization of Materials XI. Springer, Berlin, Heidelberg, 2003. 515-522.

[29]Q. Wei, B. Leblon and A.L. Rocque, "On the use of X-ray computed tomography for determining wood properties: a review," Canadian Journal of Forest Research, vol. 41, pp. 2120, Nov. 2011.

[30]F. Boero et al., "Microwave Tomography for the Inspection of Wood Materials: Imaging System and Experimental Results," IEEE Transactions on Microwave Theory and Techniques, vol. 66, pp. 3497-3510, 2018.

[31] A. M. Alani, I. Giannakis, L. Zou, L. Lantini and F. Tosti, "Reverse-time migration for evaluating the internal structure of tree-trunks using groundpenetrating radar," NDT \& E International, vol. 115, 2020.

[32] J. Ježová, L. Mertens and S. Lambot, "Ground-penetrating radar for observing tree trunks and other cylindrical objects," Construction \& Building Materials, vol. 123, pp. 214-225, 2016.
[33] Jezova J, Harou J, Lambot S. Reflection waveforms occurring in bistatic radar testing of columns and tree trunks. Construct Build Mater, vol. 174, pp. 388-400, 2018.

[34] Xiao X, Wen J, Xiao Z, Li W. Detecting and measuring internal anomalies in tree trunks using radar data for layer identification. J Sensors vol. 2018; pp. $1-11$.

[35] I. Giannakis, F. Tosti, L. Lantini and A. M. Alani, "Health Monitoring of Tree Trunks Using Ground Penetrating Radar," IEEE Transactions on Geoscience and Remote Sensing, vol. 57, pp. 8317-8326, 2019.

[36] I. Giannakis, F. Tosti, L. Lantini and A. M. Alani, "Diagnosing Emerging Infectious Diseases of Trees Using Ground Penetrating Radar," IEEE Transactions on Geoscience and Remote Sensing, 58, 1146-1155, 2020.

[37]Z. Miao and P. Kosmas, "Multiple-Frequency DBIM-TwIST Algorithm for Microwave Breast Imaging," Tap, vol. 65, pp. 2507-2516, May. 2017.

[38]C. Gilmore, A. Abubakar, Wenyi Hu, T.M. Habashy and P.M. van den Berg, "Microwave Biomedical Data Inversion Using the Finite-Difference Contrast Source Inversion Method," IEEE Transaction Antennas Propagation, vol. 57, pp. 1528-1538, May 2009.

[39] R. Solimene, I. Catapano, G. Gennarelli, A. Cuccaro, A. Dell'Aversano and F. Soldovieri, "SAR Imaging Algorithms and Some Unconventional Applications: A unified mathematical overview," IEEE Signal Processing Magazine, vol. 31, no. 4, pp. 90-98, July 2014.

[40] M. Pastorino, Microwave Imaging, Hoboken, USA: Wiley \& S., Inc, 2010.

[41]R. Pierri, A. Liseno, R. Solimene and F. Soldovieri, "Beyond physical optics SVD shape reconstruction of metallic cylinders," IEEE Transactions on Antennas and Propagation, vol. 54, no. 2, pp. 655-665, 2006.

[42] A. Liseno, F. Tartaglione and F. Soldovieri, "Shape reconstruction of 2-D buried objects under a Kirchhoff approximation," IEEE Geoscience and Remote Sensing Letters, vol. 1, no. 2, pp. 118-121, 2004.

[43] A. Liseno and R. Pierri, "Imaging of voids by means of a physical-opticsbased shape-reconstruction algorithm," J. Opt. Soc. Am. A, vol. 21, pp. 968974, 2004.

[44]G. Leucci, N. Masini, R. Persico and F. Soldovieri, "GPR and sonic tomography for structural restoration: the case of the cathedral of Tricarico," Journal of Geophysics and Engineering, vol. 8, S76-S92, 2011.

[45]T. Negishi, G. Gennarelli, F. Soldovieri, Y. Liu and D. Erricolo, "Radio Frequency Tomography for Nondestructive Testing of Pillars," IEEE Transactions on Geoscience and Remote Sensing, vol. 58, no. 6, pp. 39163926, June 2020.

[46] A.M. Alani, F. Soldovieri, I. Catapano, I. Giannakis, G. Gennarelli, L. Lantini, G. Ludeno and F. Tosti, "The Use of Ground Penetrating Radar and Microwave Tomography for the Detection of Decay and Cavities in Tree Trunks," Remote Sensing, vol. 11, pp. 2073, 2019.

[47]"Friends of Gunnersbury Park and Museum". Available online: https://gunnersburyfriends.org (Accessed 15 July 2020).

[48] "Gunnersbury Park Trees". Available online: https://gunnersburyfriends.org/gunnersbury-park-trees/ (Access 07/2020).

[49] A. Koubaa, P., Perré, R. M., Hutcheon and J. Lessard, "Complex Dielectric Properties of the Sapwood of Aspen, White Birch, Yellow Birch, and Sugar Maple”, Drying Technology, vol. 26, no. 5, pp. 568-578, 2008.

[50]W.A. Salas, J.K. Ranson, B.N. Rock and K.T. Smith, "Temporal and spatial variations in dielectric constant and water status of dominant forest species from New England", Remote Sensing of Environment, vol. 47, no. 2, pp. 109-119, 1994.

[51]I. Catapano, G. Gennarelli, G. Ludeno, F. Soldovieri and R. Persico, "Ground Penetrating Radar: Operation Principle and Data Processing," Wiley Encyclopedia of Electrical and Electronics Engineering, 1-23, 1999.

[52]R. Solimene, A. Cuccaro, A. Dell'Aversano, I. Catapano, and F. Soldovieri, "Ground clutter removal in GPR surveys," IEEE Journal of Selected Topics in Applied Earth Observations and Remote Sensing, vol. 7, no. 3, pp. 792-798, 2013.

[53] M. Bertero and P. Boccacci, Introduction to inverse problems in imaging, Inst. of Physics Publ, Bristol, 1998.

[54]C. Warren, A. Giannopoulos, and I. Giannakis. gprMax: Open source software to simulate electromagnetic wave propagation for Ground Penetrating Radar, Computer Physics Communic, 209, 163-170, 2016.

[55] F. Soldovieri, G. Prisco, and R. Persico "Application of microwave tomography in hydrogeophysics: some examples," Vadose Zone Journal, vol. 7, no. 1, pp. 160-170, 2008.

[56] R. Solimene, F. Soldovieri, G. Prisco and R. Pierri, "Three-Dimensional Microwave Tomography by a 2-D Slice-Based Reconstruction Algorithm," IEEE Geoscience and Remote Sensing Letters, vol. 4(4), 556-560, 2007.

[57] G. Gennarelli, G. Ludeno, I. Catapano, and F. Soldovieri, "Full 3-D Imaging of Vertical Structures via Ground-Penetrating Radar," IEEE Transactions on Geoscience and Remote Sensing, pp. 1-17, May 2020. 


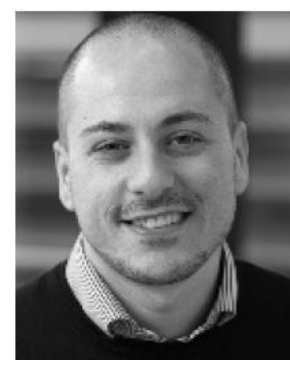

Fabio Tosti (M' 17-SM' 19) received his M.Sc. and Eng. Degrees (cum laude) in Infrastructure and Transportation Engineering at Roma Tre University, Italy, in 2010, where he also received the Ph.D. degree in Civil Engineering with European Doctorate Label (excellent rating) in 2014. He is currently a Professor of Civil Engineering at the School of Computing and Engineering, University of West London (UWL), UK and the Deputy Head of "The Faringdon Centre for Non-destructive Testing" at UWL.

Professor Tosti's research interests include the development of new algorithms, methodologies and numerical models for geoscience applications and the non-destructive and satellite remote sensing assessment, repair and maintenance of civil engineering infrastructures. He has over 170 research publication records in international journals, conferences and books and has served as Managing Guest Editor in various journals. He is a member of the editorial board of Remote Sensing and Frontiers in Remote Sensing, and the Associate Editor of the International Journal of Pavement Engineering (IJPE), Geoscientific Instrumentation, Methods and Data Systems (GI) and the Journal of Railway Engineering. He was the General Co-Chair of the 2nd International Workshop on Signal Processing Techniques for Ground Penetrating Radar Applications (SPT4GPRA 2020) in 2020 (TSP - IEEE Conference Record \#49548).

In 2017, he was a recipient of the Early Career Scientists Award by the European Geosciences Union (EGU) for "his outstanding contribution to the development of new GPR methodologies in geosciences and civil engineering". Additionally, he holds the post of Convener at the EGU General Assembly for sessions on NDT methods and data fusion.

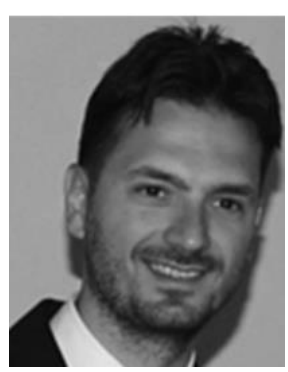

Gianluca Gennarelli received the M.Sc. degree (summa cum laude) in electronic engineering and the Ph.D. degree in information engineering from the University of Salerno, Salerno, Italy, in 2006 and 2010, respectively.

From 2010 to 2011, he was a Post-Doctoral Fellow with the University of Salerno. Since 2012, he has been a Research Scientist with the Institute for Electromagnetic Sensing of the Environment, National Research Council of Italy (IREA-CNR), Naples, Italy. In 2015, he joined NATO-CMRE, La Spezia, Italy, as a Visiting Scientist. He has co-authored more than 100 publications in international peer-reviewed journals and conference proceedings. His research interests include microwave sensors, antennas, inverse scattering problems, radar imaging, diffraction problems, and electromagnetic simulation.

Dr. Gennarelli serves as a reviewer for several international journals and conference articles.

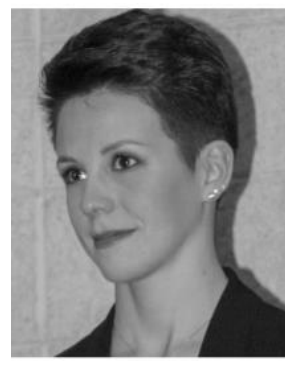

Livia Lantini (Student Member, IEEE) received the BSc (Hons.) degree in Civil Engineering and the MSc degree in Infrastructure and Transportation Engineering with the Department of Engineering, Rome Tre University, Rome, Italy. In 2021 she was awarded the PhD degree in Civil Engineering by the University of West London, London, UK.

Her research focuses on the assessment of civil engineering infrastructures using Ground Penetrating Radar (GPR) and other non-destructive testing (NDT) methods, as well as the health monitoring and assessment of trees using GPR.

She was the recipient of an award for the 'Best Paper at the IEEE 2020 43rd International Conference on Telecommunications and Signal Processing'. She has also given invited presentations at UK national events and forums, such as a Business Breakfast event at the House of Lords, in February 2020.

Dr. Lantini is also a dedicated team member of Women in Science, Technology, Engineering and Mathematics (WInSTEM) at the School of Computing and Engineering at UWL, and an Ambassador of the IEEE Women in Engineering UK \& Ireland.

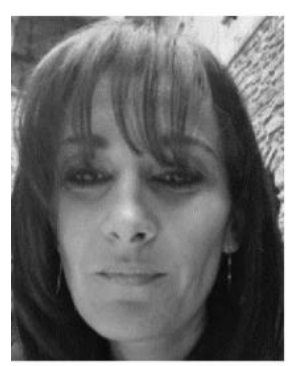

Ilaria Catapano received the Ph.D. degree in electric and information engineering from the University of Cassino, Cassino, Italy, in 2006. In 2003, in the framework of her Ph.D. project, she started her research activity with the Institute for Electromagnetic Sensing of the Environment, National Research Council of Italy (IREA-CNR), Naples, Italy, where she is a Full-Time Researcher. She was a Post-Doctoral Researcher with the Institute Fresnel of Marseille, Marseille, France, from October 2006 to March 2007. She was an Adjunct Professor of electromagnetic diagnostic with the Mediterranea University of Reggio Calabria, Reggio Calabria, Italy, in 2010, and an Invited Lecturer with São Paulo University, São Paulo, Brazil, in 2013, and also with IIT Kharagpur, Kharagpur, India, in 2016. She has co-authored more than 150 articles, mainly on scientific journals or proceedings of international conferences. Her research activities deal with noninvasive electromagnetic diagnostics and are mainly focused on models and strategies for electromagnetic forward and inverse scattering problems, development and performance assessment of microwave imaging approaches for shape reconstruction, the processing of experimental data gathered by radar systems for subsurface surveys, and $\mathrm{THz}$ spectroscopy and imaging. Dr. Catapano received the G. Barzilai Award by the Italian Electromagnetic Society in 2004. She was one of the young scientist awardees at the XXIX URSI General Assembly in 2008. She is a reviewer for several international journals and conferences.

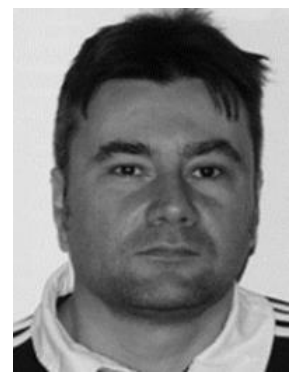

Francesco Soldovieri (Senior Member, IEEE) is a Research Director of the Institute for Electromagnetic Sensing of the Environment, National Research Council of Italy (CNR), Naples, Italy. He has co-authored about 240 articles in national and international journals and more than 350 conference proceedings. His research interests include radar imaging, data processing for groundpenetrating radar (GPR), indoor surveillance, through-wall imaging, passive radars, integration of geophysical data, and radars for planetary

exploration

Dr. Soldovieri was the General Chair of the International Workshop on Advanced Ground Penetrating Radar in 2007 and the General Co-Chair of the Ground Penetrating Radar Conference in 2010. He was a member of the Editorial Board of IEEE GEOSCIENCE AND REMOTE SENSING LETTERS (GRSL) and is a member of the Editorial Board of the IEEE TRANSACTIONS ON COMPUTATIONAL IMAGING (TCI), the IEEE TRANSACTIONS ON GEOSCIENCE AND REMOTE SENSING (TGRS), and Remote Sensing (MDPI). He is the Editor-in-Chief of HERITAGE, an MDPI Journal devoted to Cultural and Natural Heritage. He has been the Scientific Coordinator of the FP7 projects ISTIMES and AMISS and the Technical Manager of the H2020 Project HERACLES. He has been the President of the Division on Geosciences Instrumentation and Data Systems of European Geosciences Union.

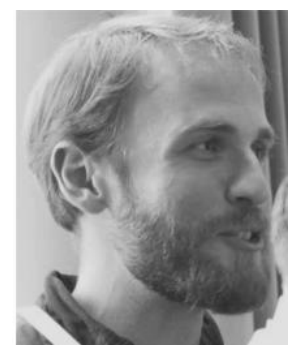

Iraklis Giannakis received the bachelor's and master's degrees in geophysics from the Aristotle University of Thessaloniki, Thessaloniki, Greece, in 2009 and 2011, respectively, and the Ph.D. degree from The University of Edinburgh, Edinburgh, Scotland, through a project co-funded by the Defense Science and Technology Laboratory, U.K., and the Engineering and Physical Sciences Research Council, U.K. He is currently a Lecturer in machine learning in geophysics at the School of Geosciences, University of Aberdeen, Aberdeen, U.K., where he has been involved in applications of ground penetrating radar (GPR) to sustainable management of forestry heritage.

His research interests include near-surface geophysics, nondestructive testing, computational electromagnetics, and machine learning. Dr. Giannakis was a recipient of the Best Paper Award at the $15^{\text {th }}$ International Conference on GPR in 2014 


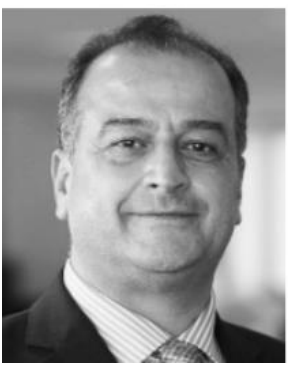

Amir M. Alani was the Rochester Bridge Trust Professor of Engineering with the University of West London, London, U.K., in 2018, where he has been the Executive Dean of the School of Computing and Engineering since 2014. He currently leads the Faringdon Center-The NonDestructive Research Centre, University of West London. He is an expert in the assessment, repair, and maintenance of civil engineering infrastructures such as bridges, tunnels, and buildings and has extensive work experience with different professional bodies in the fields of engineering and design both in the U.K. and Europe. He has more than 25 years of work experience in higher education and industry in the U.K.

He was involved in the research and development of different branches of civil and mechanical engineering, including the applications of non-destructive testing methods, concrete technology, geotechnics and soil engineering, and engineering education. He has authored or co-authored more than 180 journal papers, book chapters, international conference papers, and consulting external reports in these areas.

Prof. Alani was a Management Committee Member for a European Cooperation in Science and Technology (COST) Action project, TU1208 Project 2012-2017, "Civil Engineering Applications of Ground Penetrating Radar (GPR)." He has delivered and led numerous seminars and workshops nationally and internationally, and has chaired a number of international conference sessions in the past 20 years. 